\title{
The chemical transport model Oslo CTM3
}

\author{
O. A. Søvde ${ }^{1}$, M. J. Prather ${ }^{2}$, I. S. A. Isaksen ${ }^{1,3}$, T. K. Berntsen ${ }^{1,3}$, F. Stordal ${ }^{3}$, X. Zhu' ${ }^{2}$ C. D. Holmes ${ }^{2}$, and J. Hsu ${ }^{2}$ \\ ${ }^{1}$ Center for International Climate and Environmental Research - Oslo (CICERO), Oslo, Norway \\ ${ }^{2}$ Department of Earth System Science, University of California Irvine, California, USA \\ ${ }^{3}$ Department of Geosciences, University of Oslo, Oslo, Norway
}

Correspondence to: O. A. Søvde (asovde@ cicero.uio.no)

Received: 16 May 2012 - Published in Geosci. Model Dev. Discuss.: 19 June 2012

Revised: 26 October 2012 - Accepted: 29 October 2012 - Published: 21 November 2012

\begin{abstract}
We present here the global chemical transport model Oslo CTM3, an update of the Oslo CTM2. The update comprises a faster transport scheme, an improved wet scavenging scheme for large scale rain, updated photolysis rates and a new lightning parameterization. Oslo CTM3 is better parallelized and allows for stable, large time steps for advection, enabling more complex or high spatial resolution simulations. A new treatment of the horizontal distribution of lightning is presented and found to compare well with measurements. The vertical distribution of lightning is updated and found to be a large contributor to CTM2-CTM3 differences, producing more $\mathrm{NO}_{\mathrm{x}}$ in the tropical middle troposphere, and less at the surface and at high altitudes. Compared with Oslo CTM2, Oslo CTM3 is faster, more capable and has better conceptual models for scavenging, vertical transport and fractional cloud cover. CTM3 captures stratospheric $\mathrm{O}_{3}$ better than CTM2, but shows minor improvements in terms of matching atmospheric observations in the troposphere. Use of the same meteorology to drive the two models shows that some features related to transport are better resolved by the CTM3, such as polar cap transport, while features like transport close to the vortex edge are resolved better in the Oslo CTM2 due to its required shorter transport time step. The longer transport time steps in CTM3 result in larger errors, e.g., near the jets, and when necessary the errors can be reduced by using a shorter time step. Using a time step of $30 \mathrm{~min}$, the new transport scheme captures both large-scale and small-scale variability in atmospheric circulation and transport, with no loss of computational efficiency. We present a version of the new transport scheme which has been specifically tailored for polar studies, resulting in more accurate polar cap transport than the standard CTM3 transport, confirmed by comparison to satellite observations. In-
\end{abstract}

clusion of tropospheric sulfur chemistry and nitrate aerosols in CTM3 is shown to be important to reproduce tropospheric $\mathrm{O}_{3}, \mathrm{OH}$ and the $\mathrm{CH}_{4}$ lifetime well.

\section{Introduction}

The University of Oslo chemistry-transport model, Oslo CTM2, has been used extensively over the past decade for studies of stratospheric and tropospheric chemistry, greenhouse gases, and climate forcing (Wild et al., 2003; Gauss et al., 2003, 2006; Berglen et al., 2004; Isaksen et al., 2005; Dalsøren et al., 2007; Solberg et al., 2008; Søvde et al., 2008, 2011a; Hoor et al., 2009; Dalsøren et al., 2010; Myhre et al., 2011; Hodnebrog et al., 2011). CTM2 resulted from a collaboration between Oslo and the University of California Irvine (UCI) in which the UCI development of CTMs (Prather et al., 1987; Hall and Prather, 1993, 1995) was combined with the Oslo development of forecast meteorology fields from the European Centre for Medium-Range Weather Forecasts (ECMWF) (Sundet, 1997). The Oslo CTM2 was first documented in Jonson et al. (2001). Since CTM2, better and more efficient transport methods and diagnostics have been developed (Prather et al., 2008, 2011), and more accurate simulation of atmospheric processes, such as photolysis and scavenging, based on the ECMWF forecast data (Neu et al., 2007; Neu and Prather, 2012). These developments have been merged with CTM2's stratosphere-plustroposphere, gas-plus-aerosol, chemistry model to form the Oslo CTM3, which is documented and evaluated here.

Section 2 describes the new components of Oslo CTM3, noting the main differences from CTM2. We focus on transport and the gas-phase chemistry components, so our 
simulations will also include aerosol modules that affect chemistry directly. Section 3 evaluates the new model against some traditional chemistry climatologies and new observational case studies. We show that the inclusion of the tropospheric sulfur cycle (Berglen et al., 2004) and nitrate aerosols (Myhre et al., 2006), which directly affect the chemistry, is important for tropospheric chemistry. Also wet scavenging and transport sensitivity studies are evaluated in Sect. 3, while Sect. 4 concludes the study.

\section{Model description}

The Oslo CTM3 is a global 3-D CTM, driven by 3-hourly meteorological forecast data from the European Centre for Medium-Range Weather Forecasts (ECMWF) Integrated Forecast System (IFS) model, produced on a daily basis with $12 \mathrm{~h}$ of spin-up starting from an analysis at noon on the previous day, which are then pieced together to give a uniform dataset for a whole year. It has been clear in the history of ECMWF forecasts that there is a spin-up time for the forecasts during which short-lived phenomena like precipitation adjust to inadequate initialization from the analysis fields (Kraabøl et al., 2002; Wild et al., 2003). Forecasts also allow retrieval of additional meteorological data such as convective mass fluxes, which are not available from operational analyses. The 12-hour spin-up used here was based on ECMWF experience. The use of pieced forecasts is also imperative when running an externally forced CTM because much of the physics need to be integrated, not snapshots (e.g., 3-D clouds, convective fluxes, and precipitation fields), which are integrated from the forecast model. If analysis fields are used as the core meteorology in the CTM, then the CTM must include the full general circulation model physics (unlike here). Winds, temperature, pressure and humidity are given as instantaneous values every $3 \mathrm{~h}$, while other variables such as rainfall and convective fluxes are averages over the 3-h interval. The cycle used here is 36r1, starting from ERA-Interim re-analyses.

The 60-layer vertical resolution of the IFS is used in CTM3. The resolution near the tropical tropopause is $\sim 1 \mathrm{~km}$, and the uppermost, $10-\mathrm{km}$ thick layer is centered at $0.11 \mathrm{hPa}$ (about $60 \mathrm{~km}$ ). A horizontal Gaussian-grid of resolution T42 $\left(\sim 2.8^{\circ} \times \sim 2.8^{\circ}\right)$ is the standard resolution of CTM3, but the original resolution of the IFS (T319L60, $\sim 0.5^{\circ} \times \sim 0.5^{\circ}$ ) can also be used. The UCI/Oslo CTM framework is flexible and can be used on any 3-D quadrilateral grid.

All modelled processes, or operations, are carried out sequentially and asynchronously with the only requirement that all process sub-cycles must synch at the end of the operator-split time step, which is typically $60 \mathrm{~min}$ but can be shorter or longer. As will be explained in Sect. 2.2.1, the large-scale transport selects a maximum global time step from the Lifshitz criterion, and then sets the number of sub-
Table 1. The main model updates documented in this work.

\begin{tabular}{ll}
\hline a & $\begin{array}{l}\text { A new advection core that greatly speeds up the model, enabling } \\
\text { more complex chemistry or very-high resolution (T319) } \\
\text { chemistry simulations (Prather et al., 2008). }\end{array}$ \\
\hline b $\quad \begin{array}{l}\text { New, modernized lightning } \mathrm{NO}_{\mathrm{x}} \text { parameterizations that } \\
\text { reflect current satellite observations and recent campaigns } \\
\text { (documented here). }\end{array}$ \\
\hline c $\quad \begin{array}{l}\text { New scavenging scheme that includes liquid and ice water and } \\
\text { partially overlapping clouds (Neu and Prather, 2012). }\end{array}$ \\
\hline d $\quad \begin{array}{l}\text { New fast-JX combined with the cloud overlap scheme } \\
\text { (Neu et al., 2007) with an additional speed up from Neu's }\end{array}$ \\
$\begin{array}{l}\text { quadrature to a randomly selected cloud profile selected hourly } \\
\text { based on the cloud fractions and overlaps from the ECMWF } \\
\text { forecast data. }\end{array}$ \\
\hline e $\begin{array}{l}\text { New convection treatment using ECMWF-diagnosed } \\
\text { entrainment and detrainment, along with combining the } \\
\text { convection and large-scale vertical advection to save time and } \\
\text { reduce noise in redundant vertical transport where the inferred } \\
\text { convective subsidence nearly cancels the large-scale } \\
\text { convergence (Prather et al., 2008). }\end{array}$ \\
\hline
\end{tabular}

cycle steps, e.g., within $60 \mathrm{~min}$, meeting that criterion. For emissions, boundary layer mixing, chemistry and dry deposition (called the EBCD-sequence below), CTM3 retains the CTM2 method, with an internal cycling of maximum $15 \mathrm{~min}$. If a $60 \mathrm{~min}$ sub-step is set for the EBCD-sequence in an operator-split time step of $60 \mathrm{~min}$, the EBCD-sequence is carried out 4 times with $15 \mathrm{~min}$ time step. Note that the time step used in chemical integrations may be shorter than this (see Sect. 2.1), and does not change unless the operator-split time step is shorter than $15 \mathrm{~min}$. As an example, suppose the Lifshitz maximum time step is $42 \mathrm{~min}$, then two $30 \mathrm{~min}$ subcycle advection steps will be calculated. If e.g. the EBCDsequence is calculated every 10-min step and transport and wet scavenging request a $15-\mathrm{min}$ step, then the sub-cycle picks $1 / 12$ of $60 \mathrm{~min}$, or $5 \mathrm{~min}$, as its basic cycle. At $5 \mathrm{~min}$, there are no operations; at $10 \mathrm{~min}$, EBCD is calculated; at $15 \mathrm{~min}$, transport and wet scavenging processes are done; at $20 \mathrm{~min}, \mathrm{EBCD}$ again; at $25 \mathrm{~min}$, there are again no operations; at $30 \mathrm{~min}$ all three processes are calculated, and so on up to $60 \mathrm{~min}$.

In general, when moving from CTM2 to CTM3, there are no changes in the chemistry and aerosol modules, and the CTM2 literature still applies. Some changes are inevitable due to the new core, e.g., the new wet scavenging, and in this section we describe these changes. The main model improvements are listed in Table 1, and will be discussed in these sections: transport (Sect. 2.2), scavenging (Sect. 2.3), calculation of photodissociation rates (Sect. 2.4), emission inventories used (Sect. 2.5) and lightning $\mathrm{NO}_{\mathrm{x}}$ (Sect. 2.6). First, we give a short introduction to the chemistry and aerosol schemes. 


\subsection{Chemistry}

The chemistry of CTM3 is identical to CTM2, which has been described in earlier work, comprising comprehensive schemes for both tropospheric and stratospheric chemistry. Tropospheric chemistry was introduced by Berntsen and Isaksen (1997); stratospheric chemistry is based on Stordal et al. (1985), and the tropospheric sulfur chemistry is described by Berglen et al. (2004). The use of full tropospheric and stratospheric chemistry has been reported by, e.g., Gauss (2003), Søvde et al. (2008) and Søvde et al. (2011b). Chemical kinetics are from JPL-06 (Sander et al., 2006) and IUPAC Atkinson et al. (2004).

The tropospheric scheme is a stand-alone module, while the stratospheric module requires tropospheric chemistry to be included. Having the option to turn off stratospheric chemistry is preferable due to computational limits and when the lower troposphere is the domain of interest. In such cases, all the tropospheric trace species are advected throughout the stratosphere but without real chemistry: species that are photochemically destroyed in the stratosphere are allowed to decay at a fixed rate; species with sources in the stratosphere like $\mathrm{O}_{3}$ and $\mathrm{NO}_{\mathrm{x}}$ are set to model climatological values at CTM levels a few $\mathrm{km}$ above the tropopause, where the model climatology is produced using CTM3 with full stratospheric chemistry. This will not be described further here.

In this work, we focus on gas phase chemistry. However, as will be described, we also carry out simulations where we include aerosol modules which affect chemistry directly. These are the tropospheric sulfur module comprising sulfur chemistry and sulfate aerosols (Berglen et al., 2004), and nitrate aerosols (Myhre et al., 2006), which affect gaseous $\mathrm{HNO}_{3}$. The latter also requires sea salt aerosols to be included (Grini et al., 2002). Since the aerosol modules are unchanged from CTM2 to CTM3, we will not evaluate the aerosols here; that is left for a separate study where all available aerosol modules currently in CTM2 (e.g., Grini et al., 2002; Berglen et al., 2004; Grini et al., 2005; Myhre et al., 2006) will be evaluated (in preparation, Søvde et al., 2012). It should be noted that the tropospheric chemistry already includes a parameterization of $\mathrm{N}_{2} \mathrm{O}_{5}$ conversion to $\mathrm{HNO}_{3}$ on aerosols, and this treatment is the same in CTM3 and CTM2. The aerosol climatology used is an annual mean height-latitude distribution (Dentener and Crutzen, 1993), and while this is a crude parameterization, an update of this treatment has been outside the scope of this work.

As in CTM2, the chemical integrator is the quasi steadystate approximation (QSSA, Hesstvedt et al., 1978). Tropospheric chemistry is integrated with a maximum time step of $15 \mathrm{~min}$ (shorter if the operator-split time step is shorter), except for the OH-chemistry which uses a $1 / 3$ of this time step (Berntsen and Isaksen, 1997). Stratospheric chemistry is carried out with a maximum of $5 \mathrm{~min}$.

\subsection{Transport}

The model transport covers large-scale advection treated by the second order moments (SOM) scheme (Prather, 1986), convective transport based on Tiedtke (1989) and boundary layer mixing based on Holtslag et al. (1990). The latter is the same in both Oslo CTM3 and Oslo CTM2, and will not be described further.

\subsubsection{Advection}

In the Oslo CTM3 we have implemented the UCI CTM transport core documented by Prather et al. (2008) (P2008 from now). This new core advection scheme (P2008) is a significant advance in terms of computational efficiency and flexibility compared with the original SOM method used in CTM2 (Prather, 1986).

The 3-D advection is isotropic, i.e. it uses the same SOM algorithm in all dimensions. The zonal $(U)$ and meridional $(V)$ meteorological fields (3-h instant values) are used to compute the vertical $(W$ ) field. The CTM keeps and computes only dry-air fluxes, masses and surface pressures. Small inconsistencies in the pressure tendency compared with the convergence fields from $[U]+[V]$ are corrected by small adjustments (typically $<1 \%$ ) in $[U]$ and $[V]$ to ensure consistent mass fields (i.e., the dry-air mass is conserved and never changed except by resolved advective transport). Convection is diagnosed as updrafts and downdrafts separately, taking both entrainment and detrainment into account (see Sect. 2.2.2). The inferred residual subsidence (i.e., a $W$ like flux) is combined with the large-scale $[W]$ from the $[U]+[V]$ fields to eliminate one advection step.

Advection in each dimension is calculated as a pipe-flow as in P2008, wherein each pipe calculates its own CFL limit (i.e., flux out of a grid box cannot exceed $99 \%$ of the mass) and then if a reduced time step is required, each pipe does multi-stepped advection internally, saving large amounts of computational overhead and not requiring the global calculation to slow down for enhanced multi-stepping in the jet regions. The global advection time step, no longer limited by the CFL criteria, is now limited by the Lifshitz criterion, which is implemented here by requiring that during the sequence of advection, [Convection $+W]+[U]+[V]$, the mass of any grid box does not fall below $5 \%$ of its initial value. This new CTM3 core advection allows for dynamical time steps as large as $55 \mathrm{~min}$ on average for T42L60 $\left(\sim 2.8^{\circ}\right)$ fields and $15 \mathrm{~min}$ for T319L60 $\left(\sim 0.55^{\circ}\right)$ fields, demonstrating the advantage of being Lifshitz-limited for high-resolution CTMs. In contrast to this, the Oslo CTM2 uses the same advection time step at low and high latitudes, and therefore combined high-latitude gridboxes (so-called extended polar zones) during transport, to avoid very short global time steps. Nonetheless, the average CTM2 advection time step for the $[U]$-flux is $10 \mathrm{~min}$, and the averaging 
itself makes the treatment less optimal for polar studies, as is shown in P2008 and later in this work.

The over-the-pole flow in P2008 worked well for typical solid-body rotation tests (Williamson et al., 1992), but recently we found that under certain conditions it fails dramatically. First is the relatively large region of high- $\mathrm{N}_{2} \mathrm{O}$ air in the Arctic middle stratosphere that splits off from the tropics in March 2005 and survives into August (Manney et al., 2006), a so-called Frozen-In Anti-Cyclone (FrIAC). Second is the Arctic ozone hole of 2011 in which very low $\mathrm{O}_{3}$ columns are maintained through March and into early April. In both cases an isolated vortex (anti-cyclonic in the first, and cyclonic in the second) has an edge at the pole, and in both cases the P2008 polar advection algorithm failed to correctly transport tracers across the pole, resulting in vortex air being transported out of the vortex and air from outside transported in. With these two test cases, a new over-the-pole treatment was developed.

In the updated, improved SOM version of the P2008 advection algorithm used in CTM3, meridional advection is still calculated as a connected pipe-flow combining a meridion with its antipode complement, but over-the-pole flow at the two pie-shaped grid boxes at each pole is no longer implied. These two grid boxes are no longer combined before the $[\mathrm{V}]$ advection step, and all transport in these polar boxes is through the $[U]$-flux. Given the very small area of these polar-pie boxes, the Lifshitz limiter severely restricted the size of the global time step. Thus, each polar-pie box and its adjacent lower-latitude box are combined (conserving all moments) before both $[U]$ and $[V]$ transport, and restored to individual boxes after, assuming unchanged polar pie air mass (not tracer mass). An alternative version of the SOM polar advection, in which the polar-pie boxes are not combined with their much larger lower-latitude neighbors, is tested here and designated C3_pole. In the optional C3_pole version, the Lifshitz limiter forces global time steps of $\sim 30 \mathrm{~min}$, instead of $60 \mathrm{~min}$, and thus the polar transport is more accurate because of higher spatial resolution at the poles and shorter time steps.

\subsubsection{Convection}

Convection is calculated using information on convective mass fluxes from the meteorological data, both updrafts and downdrafts. In addition, detrainment and entrainment rates into the updrafts and downdrafts are taken into account. In an updraft (or downdraft), there may be both detrainment and entrainment at the same level, thereby working as a vent for gases as they are transported upwards (downwards). Entrainment (E) and detrainment (D) must balance the convective mass flux, so that for a given layer $\mathrm{L}$ we have

$F_{\mathrm{L}+1 / 2}-F_{\mathrm{L}-1 / 2}=\mathrm{E}_{\mathrm{L}}-\mathrm{D}_{\mathrm{L}}$

where $F_{\mathrm{L}+1 / 2}$ and $F_{\mathrm{L}-1 / 2}$ are convective mass flux through the grid box edges (positive for updrafts and negative for downdrafts). $\mathrm{L}+1$ is the level above $\mathrm{L}$. The detrainment rate $\mathrm{D}_{\mathrm{L}}$ is positive, and is retrieved from the meteorological data, along with the mass fluxes $(F)$, and from Eq. (1) we calculate $\mathrm{E}_{\mathrm{L}}$. A positive $\mathrm{E}_{\mathrm{L}}$ means entrainment occurs, while a negative $\mathrm{E}_{\mathrm{L}}$ means additional detrainment is needed to balance the net convective mass flux $\left(F_{\mathrm{L}+1 / 2}-F_{\mathrm{L}-1 / 2}\right)$.

For the CTM2, no information on detrainment rates is used; only the net entrainment $\left(E_{L}-D_{L}\right)$ is calculated from the mass fluxes. Also, the CTM2 does not use information on downdrafts. In the CTM3, however, the use of downdraft mass flux and detrainment rates may increase the mixing between the convective plume and the surroundings, as explained above. We come back to this in Sect. 3.2.2.

\subsection{Scavenging}

Scavenging covers dry deposition, i.e. uptake by soil or vegetation at the surface, and washout by convective and large scale rain. Dry deposition rates are unchanged from CTM2 to CTM3 (Wesely, 1989). However, the CTM3 uses a more detailed land use dataset, hence the weighting of deposition rates due to different vegetation categories differs from CTM2. While CTM2 uses only 5 categories in T42 horizontal resolution, the CTM3 uses the $1^{\circ} \times 1^{\circ} 18$ category ISLSCP2 MODIS dataset (9-category ISLSCP88 is also available). Differences in both resolution and vegetation fractions lead to changes up to $100 \%$ in some grid boxes, while the overall deposition rate pattern is maintained. We treat this change as part of the core update.

We will diagnose wet scavenging more closely in Sect. 3.4, but note here the main differences between CTM2 and CTM3. In general, the ratio of tracer dissolved in rain to that in interstitial air is calculated using Henry's Law. For very soluble species, such as $\mathrm{HNO}_{3}$, it is often assumed that all is dissolved. When rain containing dissolved species falls from one model gridbox into a gridbox with drier air, it will experience evaporation, depending on the amount of liquid water available (i.e., reversible evaporation). Ice scavenging, however, can be either reversible or irreversible, as explained by Neu and Prather (2012).

The CTM2 large-scale wet scavenging assumes that the gridbox fraction subject to rain $(f)$ is

$f=c_{\mathrm{f}} \frac{\text { net rain out }}{\text { cloud water }+ \text { ice }}$

where $c_{\mathrm{f}}$ is cloud fraction and net rain out is the difference between outgoing (grid box bottom) and incoming (top) rain. If net rain out is larger than the available cloud water + ice, CTM2 assumes $f=c_{\mathrm{f}}$. Then the amount dissolved, either from Henry's law or from a fixed fraction, is calculated and transported downwards. Evaporation is based on a similar approach, and occurs (reversibly) only when rain into the gridbox is larger than rain out of the grid box.

CTM3 also uses Henry's Law to calculate the amount of species dissolved in rainfall, but has a more complex cloud 
model that accounts for overlapping clouds and rain (Neu and Prather, 2012). This scheme also covers $\mathrm{HNO}_{3}$ removal on ice for temperatures $258 \mathrm{~K}<T<273 \mathrm{~K}$, for which the uptake is calculated by Henry's law modified by a retention coefficient. For temperatures below $258 \mathrm{~K}, \mathrm{HNO}_{3}$ uptake on ice follows Kärcher and Voigt (2006) (burial where tracer is uniform through the ice). A discussion on retention coefficients is given in Neu and Prather (2012); conceptually, retention implies that a fraction of the dissolved gas is retained in the ice matrix during freezing of supercooled liquid droplets. Both the retention coefficient formulation and Kärcher and Voigt (2006) burial model assume $\mathrm{HNO}_{3}$ is incorporated into the ice structure rather than adsorbed on ice surface as in Langmuir uptake (e.g., Tabazadeh et al., 1999). Further details, e.g. on evaporation, which is reversible (but possibly irreversible for ice), can be found in Neu and Prather (2012).

Convective scavenging (Berglen et al., 2004) is unchanged from CTM2 to CTM3, treating convective precipitation as rain. Splitting this precipitation into ice and liquid is beyond the scope of this work. However, due to the new model structure there are some differences in the amounts removed by convective precipitation.

\subsection{Photodissociation}

For calculation of photodissociation rates, the fast-J2 (Bian and Prather, 2002) in CTM2 has been replaced by fast-JX (Prather, 2009) in CTM3. The differences between fast-J2 and fast-JX are not tested directly here; fast-JX is treated as a part of the model core update. An important update connected to fast-JX (Photocomp2008, 2010) is the new cloud overlap treatment, described by Neu et al. (2007). The only difference from their original treatment is that instead of using multiple cloud profiles in one gridbox column, a single cloud profile is picked randomly from the possible profiles. This will be explained below.

The fast-JX scheme version 6.5 calculates photolysis rates (Js) for stratospheric and tropospheric species from the surface to $60 \mathrm{~km}$ for a single column atmosphere defined by CTM layers that can contain both absorbers $\left(\mathrm{O}_{2}\right.$, $\mathrm{O}_{3}$, aerosols) and scatterers (molecules (Rayleigh), aerosols, cloud liquid water, cloud ice water). Based on new data, solar fluxes were revised upward in the 180-240 $\mathrm{nm}$ region and thus photolysis of $\mathrm{O}_{2}$ increased, resulting in CTM3 showing better agreement with observed $\mathrm{O}_{3}$ in the stratosphere. Cross sections, quantum yields and solar fluxes are as described by Hsu and Prather (2009), using photochemistry rates from Sander et al. (2006) and cross sections from Atkinson et al. (2004). Photolysis of volatile organic compounds (VOC) is taken solely from the latter, and uses the provided individually tuned Stern-Vollmer pressure dependencies for the quantum yields. With the JPL-2010 update (Sander et al., 2011), most VOCs are now included, and the next release of fastJX (version 6.7) has a new approach for handling the Stern-
Vollmer pressure dependence of the VOC quantum yields. In version 6.7, the combined cross section plus quantum yield tables for the fast-JX wavelength bins are calculated for three troposphere temperatures with their included pressures for a typical lapse rate: $295 \mathrm{~K}(0 \mathrm{~km}, 1000 \mathrm{hPa}), 272 \mathrm{~K}(5 \mathrm{~km}$, $566 \mathrm{hPa})$, and $220 \mathrm{~K}(13 \mathrm{~km}, 178 \mathrm{hPa})$. Interpolation is done across temperature as before. It should be noted that the CTM2 fast-J2 also uses photochemistry rates from Sander et al. (2006) and cross sections from Atkinson et al. (2004).

The multi-stream scattering calculation assumes horizontally uniform layers. The J-values are generally computed at the mid-point of each layer, with the flux divergence computed between the top and bottom of each layer. When optically thick clouds occur, extra points are inserted within each CTM layer using a logarithmic scale to more accurately (and efficiently) calculate the average J-values throughout the layer.

When cloud fractions are specified for a grid box, an algorithm (Neu et al., 2007) groups the cloudy layers into maximally overlapping connected layers and randomly overlapping groups. This choice can then be used to define a number of independent, single column atmospheres, each with a fractional area. For the T42L60 fields here, the number of single column atmospheres in a box can be quite large, and is truncated to be no more than 20000 by forcing maximal overlapping clouds in the upper layers. In Neu et al. (2007) calculation of average Js over the box is done by quadrature; the fractional areas of nearly clear (cloud optical depth $<0.5$ ), hazy (cirrus), thick (stratus), and opaque (cumulus) are calculated and a sample column atmosphere from each type is selected to represent that region (i.e., Js are weighted by the fractional area of that type). Using the fractional cloud statistics from the T42L60 fields here, the number of calls to fastJX averages 2.8 per grid box (out of a maximum of 4 ).

To reduce this computational cost, a new approach is taken in CTM3, where for each grid box column a single column atmosphere is chosen randomly using its fractional area as the likelihood of being selected. The random number generator is always initialized with the same seed value so that simulations are exactly reproducible. For each three-hourly averaged statistics of cloud water and fraction, three randomly sampled single atmospheres are chosen and held fixed for $1 \mathrm{~h}$. This new random cloud-fraction algorithm has been tested against the quadrature method in the UCI CTM and found to produce results (e.g., tropospheric $\mathrm{O}_{3}, \mathrm{OH}$ ) from five parallel simulations starting with different random seeds that cluster about the quadrature method. All of these results differ clearly from the fast-J2 (CTM2) average cloud fraction approach in which there is never direct sunlight at the surface for boxes with any fractional clouds (see Neu et al., 2007).

In this work, CTM3 uses a climatology for atmospheric black carbon in the fast-JX calculations. Calculated nitrate, sulfate and sea salt aerosols do not affect the calculation of Jvalues; this will be revised when all CTM2 aerosol modules have been included into the CTM3. 


\subsection{Emissions}

In this work, the model surface emissions are taken from RETRO year 2000 (RETRO emissions, 2006), using diurnal variations for industrial emissions. We have kept the CTM2 treatment of emitting surface $\mathrm{NO}_{\mathrm{x}}$ emissions as $96 \% \mathrm{NO}$ and $4 \% \mathrm{NO}_{2}$ to account for unresolved plume processes, for historical reasons based on Petry et al. (1998). Similarly, $\mathrm{SO}_{2}$ is emitted as $97.5 \% \mathrm{SO}_{2}$ and $2.5 \%$ sulfate.

Natural emissions are taken from the POET database (Olivier et al., 2003; Granier et al., 2005), while biomass burning is taken from the Global Fires Emission Database version 3 (GFEDv3), scaled to a height distribution available from RETRO. We use monthly mean GFEDv3 data for the years 1997-2010, and we match the emissions to the meteorological year in the model. $\mathrm{NO}_{\mathrm{x}}$ emissions are emitted assuming nitrogen content to be $90 \%$ as $\mathrm{NO}$ and $10 \%$ as $\mathrm{NO}_{2}$ (Andreae and Merlet, 2001).

Monthly mean surface mixing ratios are used for $\mathrm{CH}_{4}$ due to its long lifetime, and will be discussed in Sect. 3.3.2. The mixing ratios are based on CTM2 simulations with $\mathrm{CH}_{4}$ emissions and surface deposition.

Aircraft emissions are taken from QUANTIFY, for the year 2000 (Owen et al., 2010), and are emitted as NO. No plume processes are parameterized; the CTM2 plume model was left out of this study because it was tailored to a lower resolution and hence no longer appropriate. The old plume parameterization was found to reduce aircraft induced $\mathrm{O}_{3}$ by $\sim 20 \%$ (Kraabøl et al., 2002).

Lightning $\mathrm{NO}_{\mathrm{x}}$ emissions are described in Sect. 2.6, and change daily and yearly according to the meteorological year. The climatological mean lightning source amounts to $5 \operatorname{Tg}(\mathrm{N}) \mathrm{yr}^{-1}$.

As the main purpose for this study is to document the Oslo CTM3, we keep the current emission setup with surface and aircraft emissions fixed at 2000 level. Recently more updated datasets have become available, e.g., Lamarque et al. (2010), but we will leave this for later studies.

\subsection{Lightning $\mathrm{NO}_{\mathrm{x}}$}

Lightning $\mathrm{NO}_{\mathrm{x}}\left(\mathrm{L}^{-\mathrm{NO}_{\mathrm{x}}}\right)$ emissions in the model are calculated from the convective fluxes provided by the meteorological input data. In CTM2, ${\mathrm{L}-\mathrm{NO}_{\mathrm{x}}}_{\text {emissions were calcu- }}$ lated from the product of convective mass flux and cloud-top height (Berntsen and Isaksen, 1999). CTM3 uses an updated algorithm based on cloud-top height (Price and Rind, 1992) with scaling to match lightning flash rates observed by the Optical Transient Detector (OTD, Christian et al., 2003) and Lightning Imaging Sensor (LIS, Christian et al., 1999b). L$\mathrm{NO}_{\mathrm{x}}$ is emitted as NO in both models, and at a given time $t$ the emissions are

$E(\boldsymbol{x}, L, t)=\bar{f}(\boldsymbol{x}, t) \gamma v_{L}$ where $\bar{f}(\boldsymbol{x}, t)$ is the grid-averaged lightning flash rate at the horizontal location $x$ and at time $t, \gamma$ is the $\mathrm{NO}_{\mathrm{x}}$ yield per flash, and $v_{\mathrm{L}}$ is the fraction of total column emissions occurring at level $\mathrm{L}$ (see below). We choose $\gamma=246 \mathrm{~mol} \mathrm{flash}^{-1}$, so that the mean climatological emissions are $5 \mathrm{Tg}(\mathrm{N}) \mathrm{yr}^{-1}$.

Lightning is diagnosed in the Oslo CTM3 only when convection out of the boundary layer exceeds a grid-averaged updraft velocity of $0.01 \mathrm{~ms}^{-1}$ at $\sim 850 \mathrm{hPa}$, as specified in the input meteorology. In addition, the surface must be warmer than $273 \mathrm{~K}$ and the cloud top colder than $233 \mathrm{~K}$ to support charge separation within the cloud (Williams, 1985). When these conditions are met, the in-cloud flash rate $(f)$ has the same functional dependence on cloud-top height $H(x, t)$ as in Price and Rind (1992):

$f(\boldsymbol{x}, t)= \begin{cases}\alpha_{1} H(\boldsymbol{x}, t)^{4.9} & \text { over land } \\ \alpha_{\mathrm{o}} H(\boldsymbol{x}, t)^{1.73} & \text { over ocean }\end{cases}$

Cloud-top heights in each model column are defined as the top of the highest grid box with positive upward convective mass flux. We develop new scale factors, $\alpha_{1}=3.44 \times$ $10^{-6} \mathrm{~s}^{-1} \mathrm{~km}^{-4.9}$ and $\alpha_{\mathrm{o}}=2.24 \times 10^{-3} \mathrm{~s}^{-1} \mathrm{~km}^{-1.73}$, to match the climatological flash rates over land and ocean, $35 \mathrm{~s}^{-1}$ and $11 \mathrm{~s}^{-1}$, respectively. The factors are calculated for our meteorological data over 1999-2009 (ECMWF cycle 36r1, resolution T42L60), constrained by OTD-LIS observations during 1995-2005. These coefficients differ from those reported by Price and Rind (1992) by up to a factor of 10, and must be re-calibrated for other meteorological data, and also for different resolutions, e.g. T319.

Convective fluxes, and the clouds that contain them, occupy a small fraction of the horizontal area of a model grid square. Therefore, lightning also occupies a small fraction of the model grid area. The grid-averaged lightning flash rate $(\bar{f})$ is then

$\bar{f}(\boldsymbol{x}, t)=a(\boldsymbol{x}, t) f(\boldsymbol{x}, t)$.

where $a$, the area fraction experiencing lightning, accounts for the variation in grid size with latitude and is estimated as a weighted average of the cloud fractions in the column:

$a(\boldsymbol{x}, t)=\frac{\sum_{l=1}^{l_{\mathrm{t}}} f_{\mathrm{c}, l} w_{l}}{\sum_{l=1}^{l_{\mathrm{t}}} w_{l}}$.

Here, $f_{\mathrm{c}, l}$ is the ECMWF cloudy fraction at level $l$ (McCarty et al., 2012), $w_{l}$ is the wet convective mass flux at level $l$, and $l_{\mathrm{t}}$ is the model level at the cloud top.

Figure 1 compares the lightning distributions in CTM2 and CTM3 with OTD-LIS observations. CTM3 has much less lightning over oceans than CTM2, especially around Indonesia, but still more than the observations. In both models, flash rates are underestimated in Africa and overestimated in South America, but these biases are slightly reduced in CTM3. The convective parameterization used in 

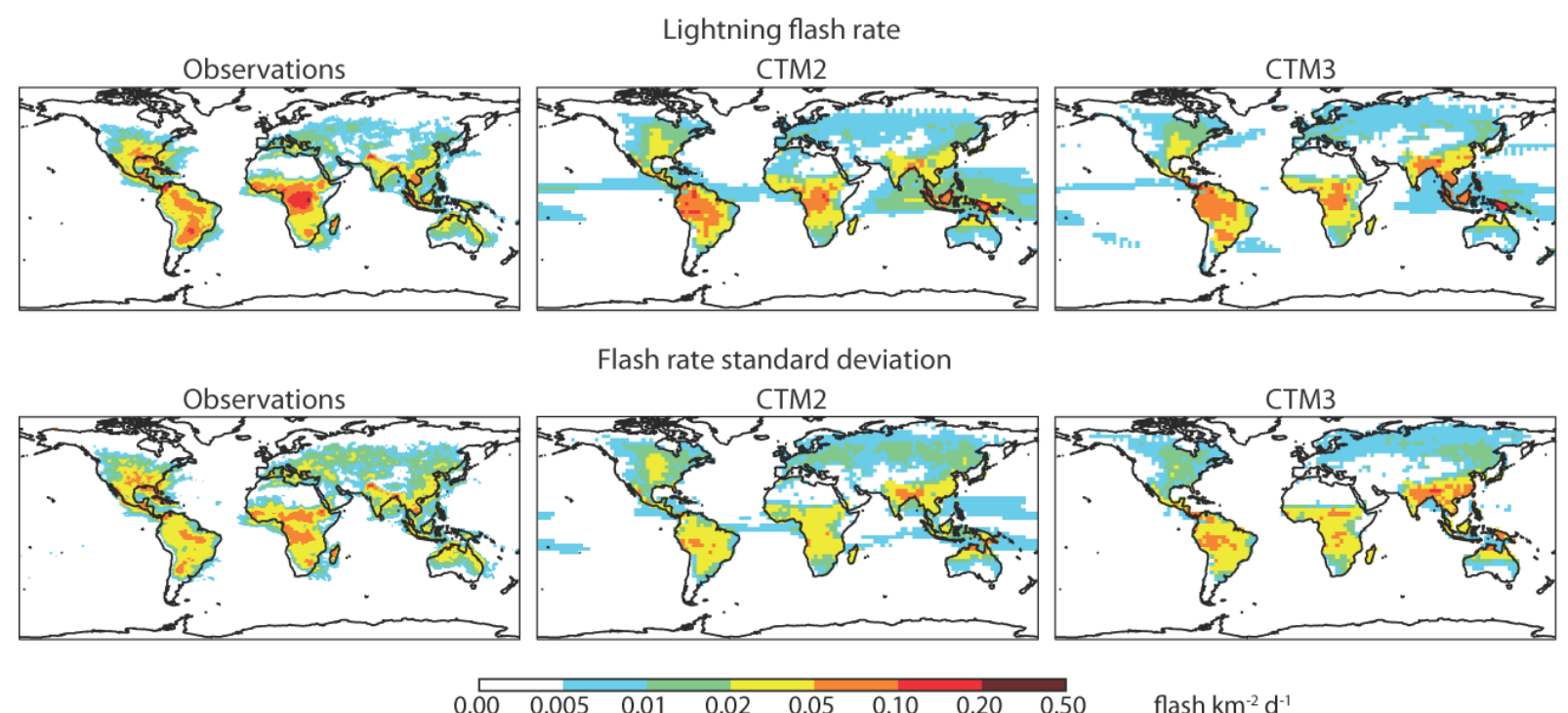

Fig. 1. Climatology of lightning flashes in observations and models. Annual mean flash rate (top) and standard deviation of monthly flash rates (bottom). Observation panels show OTD-LIS during 1995-2005. Model panels show Oslo CTM2 and Oslo CTM3 for 1999-2009.

ECMWF meteorology may contribute to these lightning biases (Barret et al., 2010), although many models with different convective schemes exhibit similar problems over these continents (Labrador et al., 2005; Tost et al., 2007). This feature could be a weakness of the Price and Rind (1992) equations; Barret et al. (2010) reported similar behavior for several models using the Price and Rind equations. CTM3 also better reproduces the seasonal north-south migration of lightning in Africa, as seen in the monthly standard deviations (Fig. 1, bottom row). Overall, the spatial distribution of L-NOx emissions in CTM2 and CTM3 are similar, but CTM3 better matches the OTD-LIS observations.

The model distributes $\mathrm{L}_{-} \mathrm{NO}_{\mathrm{x}}$ emissions vertically through the convective column according to observed profiles (Ott et al., 2010) for 4 world regions. These profiles are scaled vertically to match the height of each convective plume in the CTM and already account for vertical mixing of lightning $\mathrm{NO}_{\mathrm{x}}$ within the cloud. Geographic region definitions are from Allen et al. (2010) and Murray et al. (2012).

The old vertical profiles (Pickering et al., 1998) injected a large fraction of ${\mathrm{L}-\mathrm{NO}_{\mathrm{x}}}_{\mathrm{x}}$ near the surface and near the convective cloud top. In contrast, the new vertical profiles (Ott et al., 2010), which are based on more extensive in situ measurements, place most $\mathrm{L}-\mathrm{NO}_{\mathrm{x}}$ below the convective cloud top with little near the surface. While the new $\mathrm{L}-\mathrm{NO}_{\mathrm{x}}$ algorithm scales the new profiles to match the cloud-top heights hourly in each CTM column, the old CTM2 algorithm assumed a fixed convective top at $16 \mathrm{~km}$ for purposes of calculating the vertical distribution of $\mathrm{L}-\mathrm{NO}_{\mathrm{x}}$. Thus, CTM2 placed much more $\mathrm{L}^{-\mathrm{NO}_{\mathrm{x}}}$ in near the tropopause, or even in the stratosphere when the tropopause was below $16 \mathrm{~km}$. The change in $\mathrm{L}^{-\mathrm{NO}_{\mathrm{x}}}$ between CTM3 and CTM2 is extensive, includ- ing location, flash-rate and scaling factors as well as vertical profiles of the injected NO.

We have tested the change in profiles in CTM3, and found that compared to the old profiles (Pickering et al., 1998), the Ott et al. (2010) profiles cause modelled zonal mean $\mathrm{NO}_{\mathrm{x}}$ to increase by up to $10-15 \%$ (annually up to $\sim 10 \%$ ) in the middle troposphere $(400-800 \mathrm{hPa})$, and decrease $\mathrm{NO}_{\mathrm{x}}$ by up to $15-25 \%(\sim 15 \%$ annually $)$ in the tropical upper troposphere $(250-100 \mathrm{hPa})$. Accompanying $\mathrm{O}_{3}$ changes range from $-2 \%$ to $2 \%$. However, scaling the old profiles to fixed $16 \mathrm{~km}$ convective cloud tops has a larger effect, increasing $\mathrm{NO}_{\mathrm{x}}$ by more than $100 \%$ at $\sim 200 \mathrm{hPa}$ and $\mathrm{O}_{3}$ by $\sim 35 \%$ at $400 \mathrm{hPa}$. We come back to this in Sect. 3.3.

\section{Evaluation}

Here we evaluate the Oslo CTM3 against the Oslo CTM2 and measurements. The comparison is carried out in several steps, focusing first on the stratosphere and then on the troposphere, before looking at a number of diagnostics. For this study, we have carried out several full chemistry-transport simulations, listed in Table 2. Also listed are the time spans simulated for the different runs. CTM3 and CTM2 are driven by the same meteorological dataset.

The main runs are C3, C3_ssn, C2 and C2_ssn, and the others are sensitivity studies. The ssn-simulations include sulfur chemistry (Berglen et al., 2004), sea salt aerosols (Grini et al., 2002) and nitrate aerosols (Myhre et al., 2006). As will be explained, the $\mathrm{C} 3$ simulation produces higher tropospheric $\mathrm{OH}$ and $\mathrm{O}_{3}$ than $\mathrm{C} 2$, due to less removal by wet scavenging (e.g., $\mathrm{HNO}_{3}$ and $\mathrm{H}_{2} \mathrm{O}_{2}$ ), different vertical distribution of lightning, and more active photochemistry. This 
Table 2. Description of the full transport-chemistry simulations in this study. The notation C2 and C3 represents CTM2 and CTM3, respectively. Lightning parameterizations are described in Sect. 2.6 The $[U]$-wind time step annual average for year 2005. "SSN" denotes "sea salt, sulfate and nitrate". * C3_1/4 was started from C3_1/2 at 1 Jan 2005.

\begin{tabular}{lccccccc}
\hline Simulation & Start & End & $\begin{array}{c}\text { Lightning } \\
\text { (see text) }\end{array}$ & $\begin{array}{c}\text { Detrainment } \\
\text { rates used? }\end{array}$ & $\begin{array}{c}\text { Chemistry } \\
\text { Trop/Strat/SSN }\end{array}$ & $\begin{array}{c}\text { Operator-split } \\
\text { time step }\end{array}$ & $\begin{array}{c}{[U] \text {-flux }} \\
\text { time step }\end{array}$ \\
\hline C3 & 1 Jan 1997 & 31 Dec 2005 & OTT & Yes & Y/Y/N & $60 \mathrm{~min}$ & $55 \mathrm{~min}$ \\
C3_ssn & 1 Jan 1997 & 31 Dec 2005 & OTT & Yes & Y/Y/Y & $60 \mathrm{~min}$ & $55 \mathrm{~min}$ \\
C2 & 1 Jan 1997 & 31 Dec 2005 & C2PIC & no & Y/Y/N & $60 \mathrm{~min}$ & $10 \mathrm{~min}$ \\
C2_ssn & 1 Jan 1997 & 31 Dec 2005 & C2PIC & no & Y/Y/Y & $60 \mathrm{~min}$ & $10 \mathrm{~min}$ \\
C3_1/2 & 1 Nov 2004 & 31 Dec 2005 & OTT & Yes & Y/Y/N & $30 \mathrm{~min}$ & $30 \mathrm{~min}$ \\
C3_1/4 & 1 Jan 2005* & 31 Dec 2005 & OTT & Yes & Y/Y/N & $15 \mathrm{~min}$ & $15 \mathrm{~min}$ \\
C3_pole & 1 Nov 2004 & 31 Dec 2005 & OTT & Yes & Y/Y/N & $60 \mathrm{~min}$ & $29 \mathrm{~min}$ \\
\hline
\end{tabular}

motivated the inclusion of the ssn-studies, which were known to reduce $\mathrm{OH}$. Comparisons with observations will in general be made with C3_ssn and C2_ssn, although we will also comment on $\mathrm{C} 3$ and $\mathrm{C} 2$ when these differ from the ssn-results.

The sensitivity studies are all without sulfur and nitrate aerosols, included to assess the CTM 3 transport, and are compared with $\mathrm{C} 3$. $\mathrm{C} 3 \_1 / 2$ is the $\mathrm{C} 3$ run with an operatorsplit time step of $30 \mathrm{~min}$, i.e. half of that in C3. It is included to assess transport errors. Similarly, we carry out a 12 month C3_1/4, starting at 1 January 2005 from the C3_1/2 simulation, for testing the convergence of operator-split time steps. C3_pole is the $\mathrm{C} 3$ run with the optional more accurate polar cap treatment described in Sect. 2. As mentioned in Sect. 2, CTM3 transport is stable for longer time steps than CTM2, and may produce larger errors e.g. around jet streams. It is the $[U]$-flux time step that largely controls these errors, and from Table 2 we also show how these differ for the different CTM3 setups.

For the main runs, the simulated period is 1997-2005, while the other runs are 14-months simulations starting from the instant C3 field at 1 November 2004 (except the 12month C3_1/4, started from C3_1/2 at 1 Jan 2005). The first year (1997) was started from an already spun-up simulation, more specifically from an instant snapshot of all species at 1 January 2005, and should therefore be considered as spinup. The year 2005 was chosen because the Northern Hemisphere meteorological conditions were somewhat similar to 1997.

\subsection{Stratosphere}

For the evaluation of the stratosphere, we first consider the stratospheric age of air and how the age tracers differ from CTM2 to CTM3. In addition, we carry out comparisons with satellite measurements. It should be noted that in the stratosphere, C3_ssn and C3 are only negligibly different because their main differences are in the troposphere.

\subsubsection{Age of air}

The UCI CTM/Oslo CTM3 stratospheric age of air was presented by Prather et al. (2011), using an older cycle of the
ECMWF IFS meteorology, and for a different year. In the tests here with CTM2 and CTM3, the purpose of examining age of air is to identify differences in the tracer transport algorithm and the impact of polar treatment and time step. All versions use the identical three-hour meteorological data. Our intent is not to evaluate these met fields against observations of tracers that approximate the age of air (e.g., $\mathrm{SF}_{6}$, $\mathrm{CO}_{2}$ ), but to examine how different numerics can produce different values (e.g., P2008). We calculate stratospheric age of air from a tracer that is forced to be linearly increasing in the lower tropical troposphere (Hall et al., 1999). The age is calculated for T42 horizontal resolution, and the transport runs are similar to the runs listed in Table 2.

Simulations of 20 years were carried out using 2005 meteorology recycled annually, and age of air was calculated from the linearly increasing source in the tropical troposphere. Note that the use of a tropical source gives greater north-south symmetry in the lower stratosphere than from northernly-only sources used in observations, see Prather et al. (2011). Annual zonal means of age of air are shown in Fig. 2 for CTM3 and CTM2, with operator-split time step of one hour (C3 and $\mathrm{C} 2$ ), along with $\mathrm{C} 3 \_1 / 2$ where the time step is $30 \mathrm{~min}$. In general, the maximum age value is slightly smaller in CTM3. However, the main difference between CTM3 and CTM2 can be found in the Southern Hemisphere for ages older than $4 \mathrm{yr}$, where the CTM2 produce a southward tongue of younger air at around $40^{\circ} \mathrm{S}-70^{\circ} \mathrm{S}$ and $50 \mathrm{hPa}-10 \mathrm{hPa}$ altitude. This feature is not captured by $\mathrm{C} 3$, but is better captured in $\mathrm{C} 3 \_1 / 2$, where the shorter operatorsplit time step reduces the errors, especially around the polar jets (Prather et al., 2008). Between C3 and C2, the maximum age difference in this region amounts to $0.67 \mathrm{yr}$, as shown in Fig. 3a. By halving the operator-split time step as in C3_1/2, the maximum difference to $\mathrm{C} 2$ at this location is reduced to $0.29 \mathrm{yr}$ (Fig. 3b). An operator-split time step of $15 \mathrm{~min}$ reduces the difference to $\mathrm{C} 2$ further to $0.12 \mathrm{yr}$ (Fig. 3c). Thus, the error induced by a finite time step can be readily evaluated from the sequence $\mathrm{C} 3, \mathrm{C} 3 \_1 / 2, \mathrm{C} 3 \_1 / 4$, and it is not clear whether the differences in Fig. $3 \mathrm{c}$ are from errors in $\mathrm{C} 3 \_1 / 4$ or $\mathrm{C} 2$. 


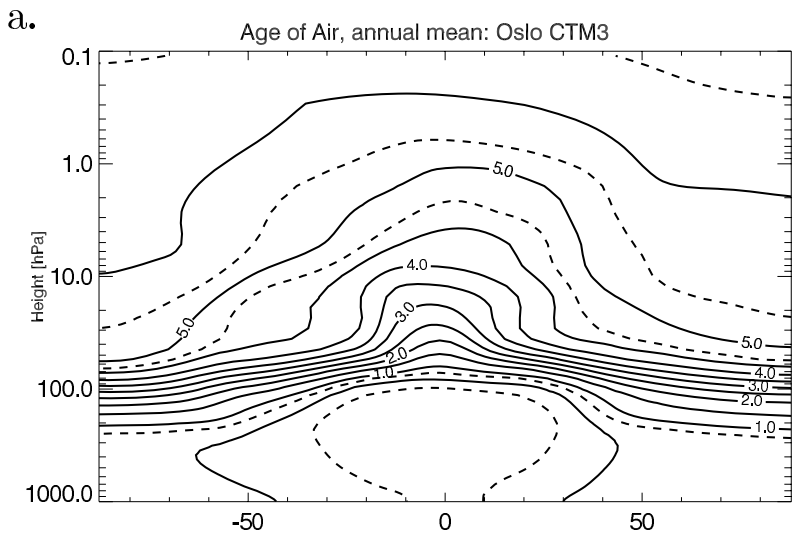

b.

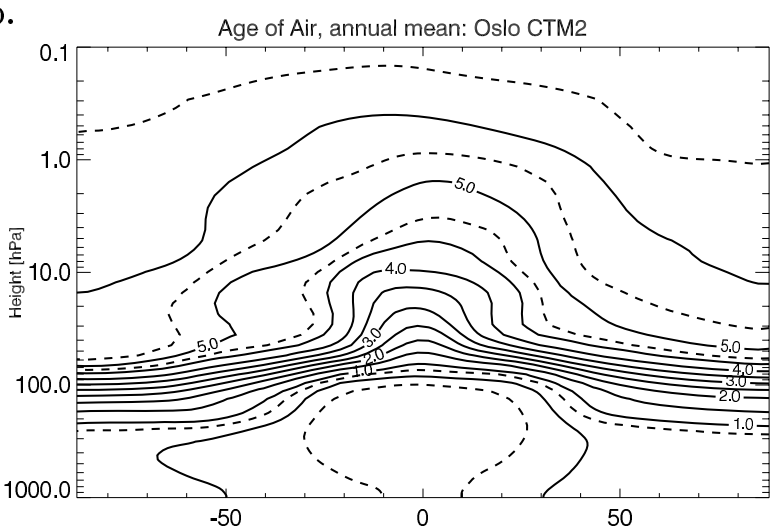

c.

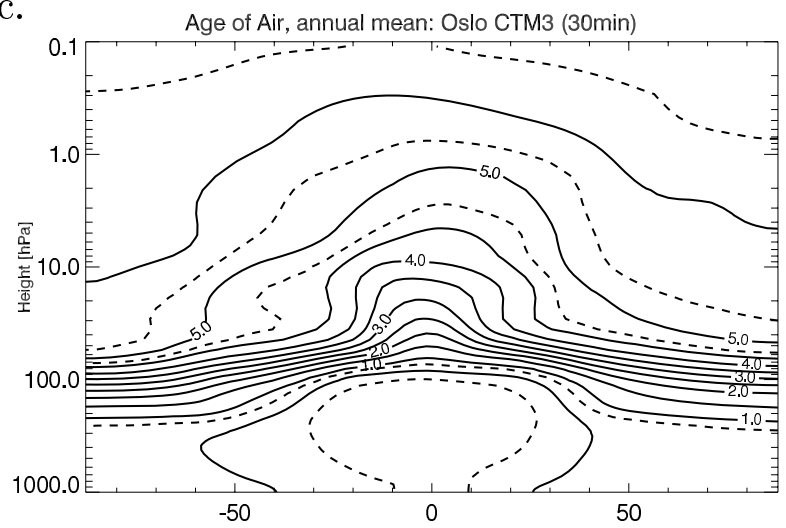

Fig. 2. Annual zonal mean age of air based on a tropical source tracer increasing linearly with time, after $20 \mathrm{yr}$ of transport, resolution T42L60. (a) CTM3, (b) CTM2 and (c) CTM3 with 30 min operator-split time step.

Whereas a comparison of $\mathrm{C} 3 \_1 / 2$ against $\mathrm{C} 3$ shows a noticeable improvement when reducing the time step, the improved polar cap transport (C3_pole) only changes the stratospheric age of air slightly (not shown). From a latitude/longitude view, the difference between CTM2 and CTM3 at $\sim 50 \mathrm{hPa}$ (not shown) is found around the polar vortex edge, indicating that the vortices are more closed off
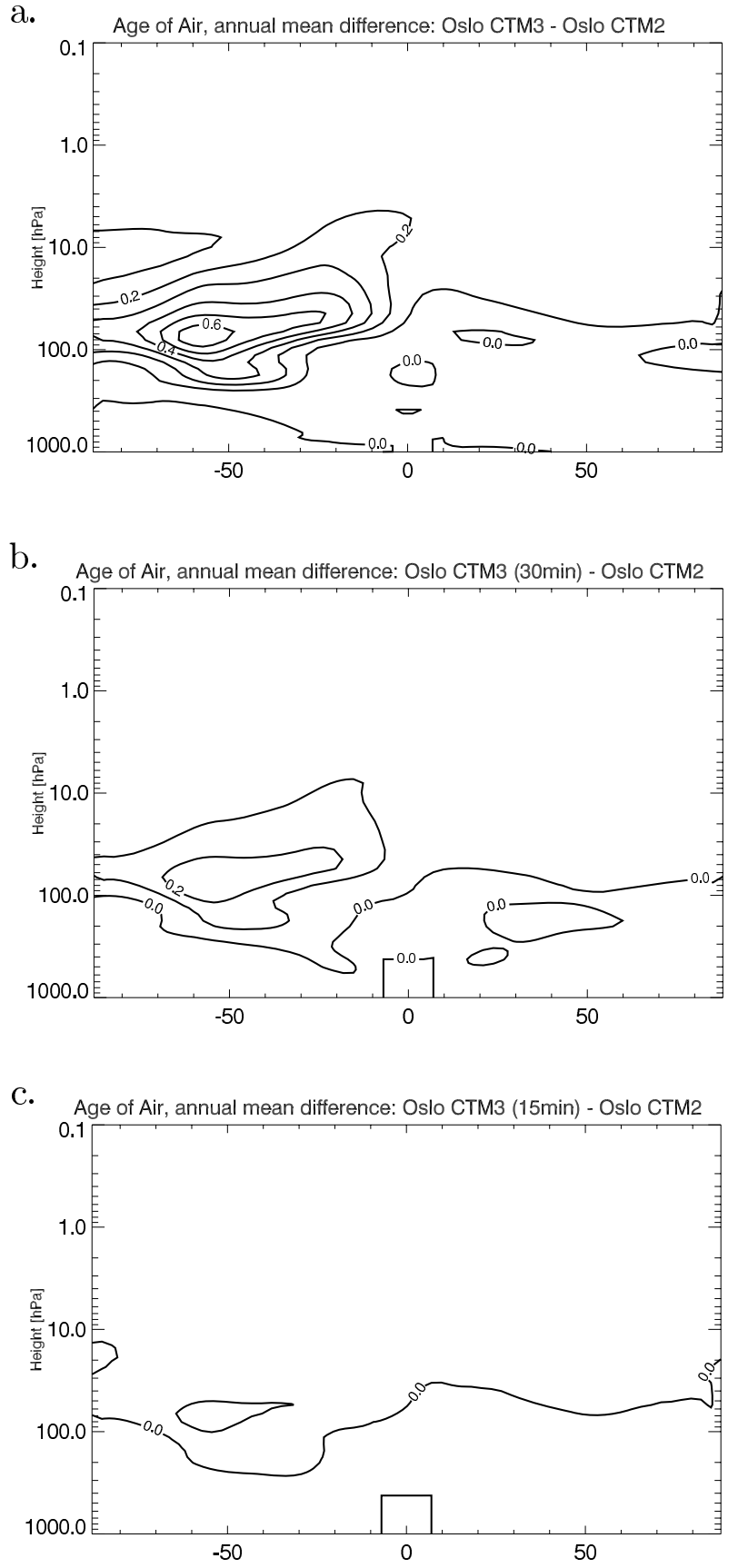

Fig. 3. Difference in annual zonal mean age of air between $\mathrm{C} 3$ and $\mathrm{C} 2$ (a), $\mathrm{C} 3 \_1 / 2$ and $\mathrm{C} 2$ (b) and $\mathrm{C} 3 \_1 / 4$ and $\mathrm{C} 2$ (c).

in CTM2. Halving the time step removes most of this dissimilarity (Prather et al., 2008), consistent with the better resolved tongue of younger air seen in Fig. 2c.

This indicates that CTM 3 should be run with a $15 \mathrm{~min}$ or 30 min operator split time-step in order to capture the correct distribution and transport at the polar vortices. We come back to this in Sect. 3.5. 


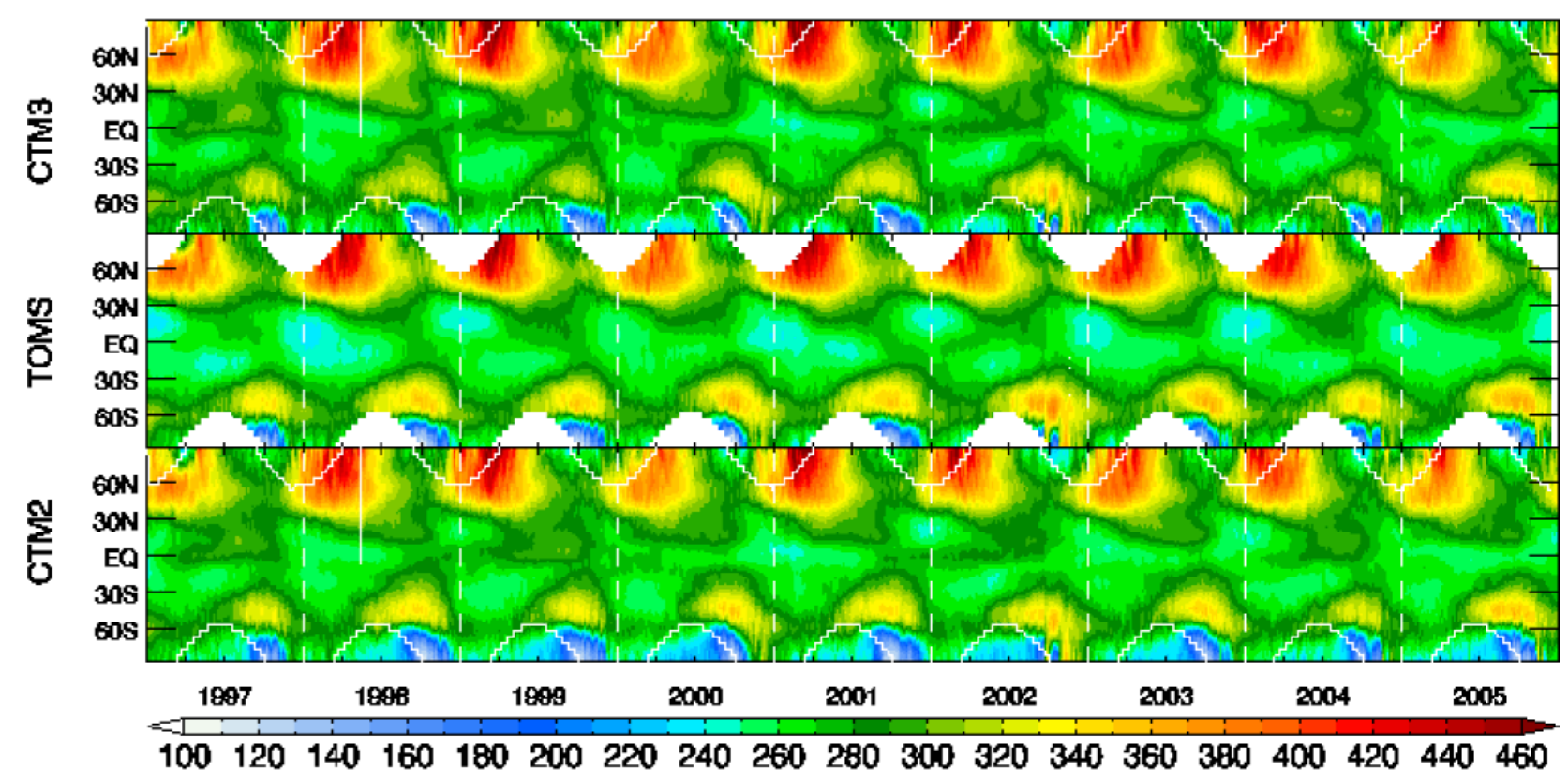

Fig. 4. Daily zonal mean total $\mathrm{O}_{3}$ column (Dobson Units) for C3_ssn (top), TOMS (middle) and C2_ssn (bottom), from 1997 through 2005.

\subsubsection{Comparisons with satellites}

In Fig. 4 we show the interannual variability of the daily zonal mean $\mathrm{O}_{3}$ column, from 1997 to 2005, where model results from CTM3 (C3_ssn) and CTM2 (C2_ssn) are compared to Total Ozone Mapping Spectrometer (TOMS) instrument, available from http://mirador.gsfc.nasa.gov/. Figure 4 shows clearly that the models produce reasonable polar $\mathrm{O}_{3}$ loss, as previously reported (Søvde et al., 2008, 2011b; Balis et al., 2011). Other features that are driven by the meteorological dynamics and the seasonality of the amount of sunlight available can also be seen, such as the Antarctic Ozone Hole split in 2002 .

By closer examination, we see that the Oslo CTM3 and CTM2 $\mathrm{O}_{3}$ columns in general agree well with TOMS in the Northern Hemisphere (NH). At Southern Hemisphere (SH) mid-latitudes, CTM3 is somewhat lower than observed and CTM2 seem to reproduce TOMS better, confirming that CTM2 has a somewhat more closed-off polar vortex, and that the CTM3 transport errors are larger near the SH polar jet. In 2002, however, when the Antarctic $\mathrm{O}_{3}$ hole was smaller and also split in two, the models are more similar at SH midlatitudes, indicating that the over-shooting winds were less pronounced. In Fig. 5 we show the CTM3 vs. CTM2 difference for year 2005, for different operator-split time steps in CTM3. Clearly, CTM3 converges towards CTM2 for shorter time steps, with the $15 \mathrm{~min}$ time step close to the $\sim 10 \mathrm{~min}$ $[U]$-flux time step in CTM2. We note, however, that CTM2 does not necessarily show the truth and also has its errors, especially near the pole where CTM3 resolves transport better.

The use of real meteorological data allows a more thorough comparison on a one-to-one basis. As an example, we show in Fig. 6 the daily average total $\mathrm{O}_{3}$ column for 28 November 2000, when an $\mathrm{O}_{3}$ mini-hole occurred over Europe (Semane et al., 2002). Both CTM3 and CTM2 reproduce this event well and to a better degree than in Søvde et al. (2008), which had too high $\mathrm{O}_{3}$ columns for Northern Europe towards Siberia. This improvement is mainly due better stratospheric circulation in the 60-layer meteorological data used here compared to the 40-layer data used in Søvde et al. (2008).

It can be seen in Fig. 6 that the CTM2 produces almost uniform polar caps due to its transport treatment. CTM3, however, does not, and reproduces, e.g., the Antarctic low- $\mathrm{O}_{3}$ tongue at about $170^{\circ} \mathrm{E}$ to a better degree. In agreement with Fig. 4, the SH mid-latitude maximum is somewhat higher in CTM2. Similar features can be found in 2005, where we have found that this bias is reduced in C3_1/2.

The Oslo CTM3 mostly produces higher column values than CTM2, the latter having a slightly lower stratospheric $\mathrm{O}_{3}$. This is shown in Fig. 7, where the models are compared to Earth Observing System Microwave Limb Sounder (MLS) version 3.3 observational data (Froidevaux et al., 2008; Livesey et al., 2011). Zonal means for 30-degree latitude bands $\left(60^{\circ}\right.$ for the tropics) are given for January 2005 and July 2005, with standard deviation shown as horizontal bars. CTM2 standard deviation is not shown; it is similar to CTM3. For $\mathrm{O}_{3}$ (Fig. 7a), CTM3 reproduces MLS better than CTM2 due to the updated photolysis treatment. The sensitivity studies C3_1/2 and C3_pole produce negligibly different profiles (not shown).

In Fig. 7b we compare the models with $\mathrm{MLS} \mathrm{HNO}_{3}$ measurements (Santee et al., 2007; Livesey et al., 2011), where 
a.

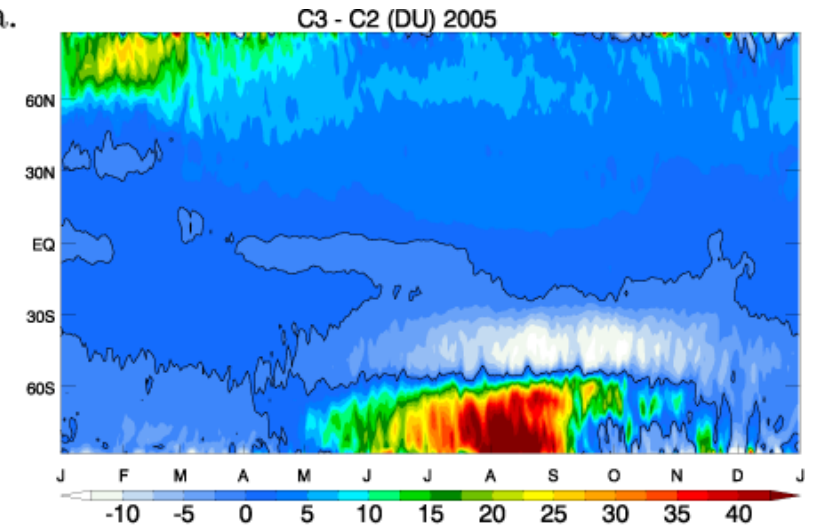

b.

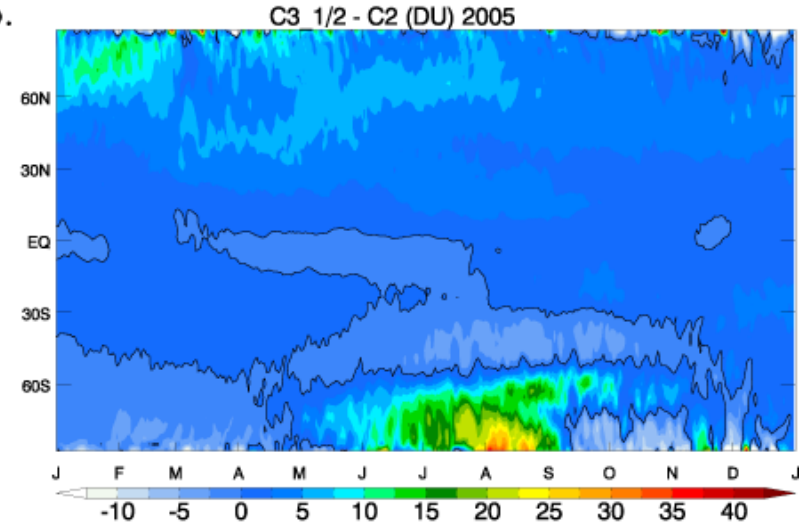

c.

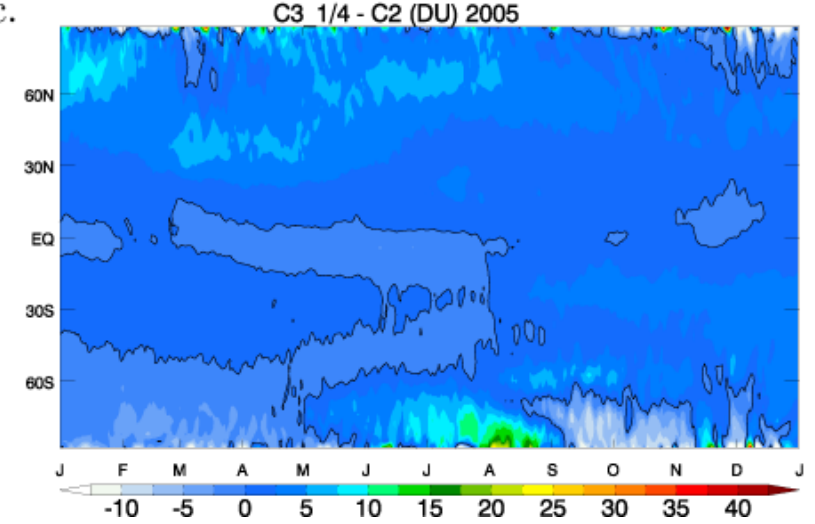

Fig. 5. Convergence of the CTM 3 operator-split time step, shown by the difference in daily zonal mean total $\mathrm{O}_{3}$ column (Dobson Units) between CTM3 runs with different operator-split time steps and CTM2, for the year 2005. (a) C3 (60 min) vs. C2 (b) C3_1/2 (30 $\mathrm{min})$ vs. C2 and (c) C3_1/4 (15 min) vs. C2.

the CTM3 and CTM2 reproduce MLS well in summer but underestimate at altitudes above $30 \mathrm{hPa}$ in winter. The CTMs already include $\mathrm{NO}_{\mathrm{x}}$ conversion to $\mathrm{HNO}_{3}$ on background aerosols (Søvde et al., 2008), so an underestimation of $\mathrm{HNO}_{3}$ in winter may, e.g., be due to lack of nitrogen species transported downwards from the mesosphere (Randall et al., 2006, 2009), or the lack of in-situ $\mathrm{NO}_{\mathrm{x}}$ sources caused by energetic particle precipitation (Jackman et al., 2008; Semeniuk et al., 2011) and conversion to $\mathrm{HNO}_{3}$ by, e.g., ion clusters (Verro- nen et al., 2008, 2011). Below $30 \mathrm{hPa}$ the models do fairly well, also when it comes to the standard deviation. There are no big differences between CTM2 and CTM3, although CTM3 seems to perform slightly better in summer. Again, C3_pole and $\mathrm{C} 3 \_1 / 2$ produce almost identical profiles, except the latter at $\mathrm{SH}$ high latitudes, where small differences up to $5 \%$ in $\mathrm{HNO}_{3}$ can be seen (not shown).

Lastly, we compare modelled $\mathrm{N}_{2} \mathrm{O}$ with MLS measurements (Lambert et al., 2007; Livesey et al., 2011), as shown in Fig. 7c. CTM3 and CTM2 produce very similar distributions of $\mathrm{N}_{2} \mathrm{O}$. However, at all latitudes except high wintertime latitudes, both models underestimate $\mathrm{N}_{2} \mathrm{O}$ between about $30 \mathrm{hPa}$ and $1 \mathrm{hPa}$, indicating slower Brewer-Dobson circulation in the meteorological data, particularly for upward motion in the tropics. Again there are negligible differences to C3_1/2 and C3_pole. An earlier cycle of meteorological data (cycle 29) shows slightly better comparison (not shown), which could indicate that cycle $36 \mathrm{r} 1$ has slower vertical transport in the tropics. Monge-Sanz et al. (2012) also found slower Brewer-Dobson circulation in the ERA-Interim forecasts (cycle 31r2), producing too old stratospheric air in the tropics at $18-22 \mathrm{~km}$ altitude. They found that the reanalysis produces better age of air in the tropics, but that forecasts are better at other latitudes. We will come back to the slow Brewer-Dobson circulation in the next sections.

\subsubsection{Modelling a Frozen-in Anti-Cyclone}

An important change from CTM2 to CTM3 is the better polar transport treatment, and to demonstrate this we look at the 2005 Frozen-in Anti-Cyclone (FrIAC) in the Arctic reported by Manney et al. (2006) and more recently studied by Allen et al. (2011). In Fig. 8 we show a Hovmöller plot, as in Allen et al. (2011), of $\mathrm{N}_{2} \mathrm{O}$ at the altitude $850 \mathrm{~K}$ and latitude $78^{\circ} \mathrm{N}$, measured by MLS, and modelled by the Oslo CTM3 and the Oslo CTM2. MLS measurements have been binned into $5 \times 5^{\circ}$ latitude/longitude bins due to the sparsity of observations. $\mathrm{N}_{2} \mathrm{O}$ from the CTMs were put out hourly in 3-D and interpolated to $78^{\circ} \mathrm{N}$. Note that the color scale range of $0-175 \mathrm{ppb}$ is larger than in Allen et al. (2011). We have added contours of $75 \mathrm{ppb}$ and $100 \mathrm{ppb}$ to make a comparison easier.

The Oslo CTM3 reproduces transport of the high- $\mathrm{N}_{2} \mathrm{O}$ intrusion well, although the mixing ratio amplitude is underestimated by $40-60 \mathrm{ppb}$. As shown in Fig. 7, $\mathrm{N}_{2} \mathrm{O}$ was in general underestimated between $30 \mathrm{hPa}$ and $1 \mathrm{hPa}$ at most latitudes, which could explain the overall low $\mathrm{N}_{2} \mathrm{O}$ abundances relative to observations in Fig. 8. This could render $\mathrm{N}_{2} \mathrm{O}$ values too low even before entering the polar latitudes. The Oslo CTM2 does not capture this transport well. Its transport pattern is similar to CTM3, but due to the averaging of the polar gridboxes, where the $\mathrm{N}_{2} \mathrm{O}$ is smeared out, the values are substantially lower than for CTM3.

From sensitivity studies, we have found (but not shown) that halving the operator-split time step (C3_1/2) does not change the CTM3 performance in terms of the $\mathrm{N}_{2} \mathrm{O}$ levels 


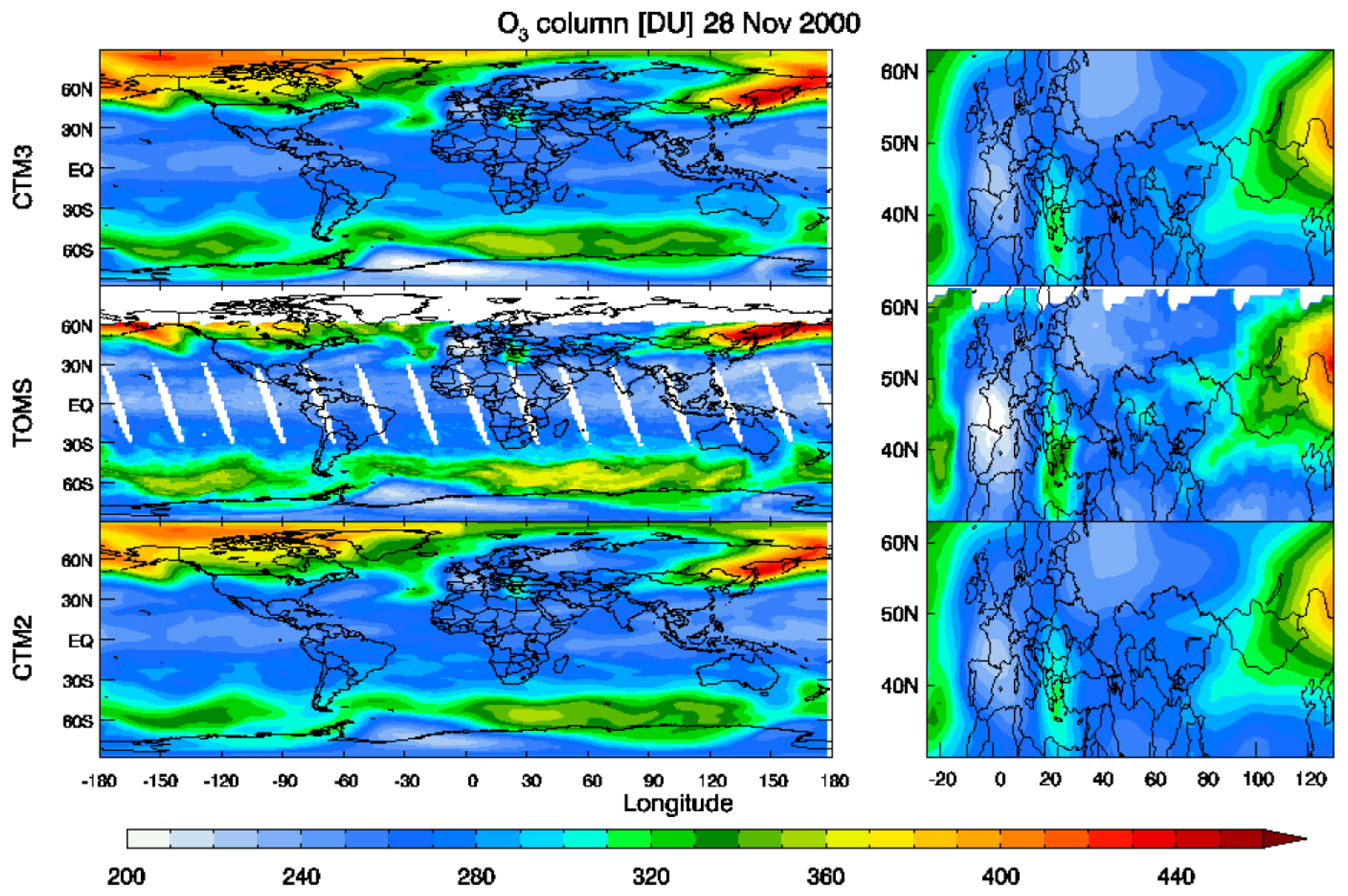

Fig. 6. Daily mean total $\mathrm{O}_{3}$ column for C3_ssn (top), TOMS (middle) and C2_ssn (bottom), 28 November 2000.

in the FrIAC. This is mainly because the FrIAC was located above the region where main transport differences between $\mathrm{C} 3$ and C3_1/2 are found. However, the improved polar transport (C3_pole) produces up to $30 \%$ more $\mathrm{N}_{2} \mathrm{O}$ in the FrIAC after 1 May. In general, the differences arise when large wind gradients are located across the combined grid boxes in CTM3 transport.

Studies involving polar cap transport, and to some extent Arctic and Antarctic studies, will clearly benefit from using C3_pole transport, while other studies may benefit from the shorter computing time achieved by combining polar boxes, and find its performance acceptable.

\subsection{Troposphere}

In this section we focus on the troposphere, describing transport differences between Oslo CTM 3 and CTM2 and also compare the models with observations.

\subsubsection{Transport in the troposphere}

CTM3 and CTM2 are expected to differ slightly in the troposphere due to the differences in transport treatment. We have studied the linearly increasing age of air tracer for year 20 , and in the zonal mean C3 differs from C2 by only $\sim 0.5 \%$ between the surface and $\sim 300 \mathrm{hPa}$ (not shown). In general the
CTM3 tropospheric mixing ratios are slightly higher south of $50^{\circ} \mathrm{S}$, indicating slightly faster transport to southernmost latitudes. North of $50^{\circ} \mathrm{S}$ the differences are generally related to convective regions, where CTM2 has higher mixing ratio than CTM3 in the lower troposphere. This is mainly due to differences in entrainment and detrainment, and will be explained in Sect. 3.2.2.

\subsubsection{Convective transport}

Recently, Hoyle et al. (2011) presented convective tracer transport using different CTMs, among them the Oslo CTM2, using a different set of meteorological data than used here. To compare the differences in transport between Oslo CTM3 and CTM2, we do similar tracer studies with one tracer held constant at $1 \mathrm{ppm}$ below $500 \mathrm{~m}$ altitude and above having a lifetime of $6 \mathrm{~h}$ (T6h), and a second 20-days lifetime tracer held constant at $1 \mathrm{ppt}$ at the surface (T20d).

Both models have an overall operator-split time step of $60 \mathrm{~min}$, where large-scale advection is treated for $60 \mathrm{~min}$ and then boundary layer mixing for $4 \times 15 \mathrm{~min}$. Constant T6h and T20d values (as described above) are set before every 15min boundary layer mixing step, so that each mixing step will not experience a surface layer with almost no T6h or T20d tracer available. This is mainly important for T20d, which is only set in the surface layer. The T6h and T20d results 
a.
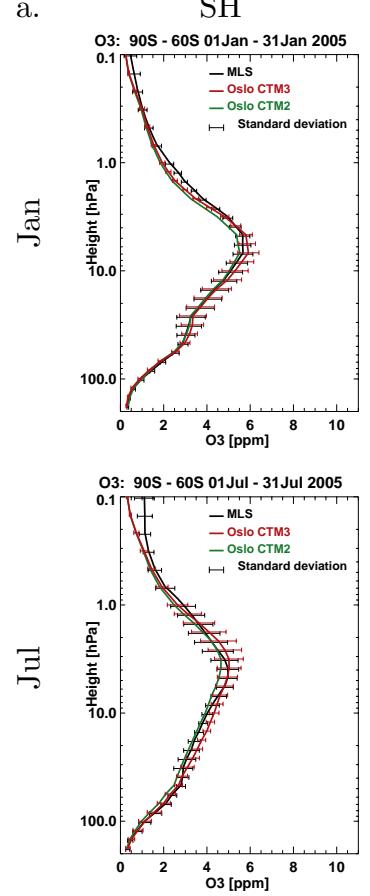

SM

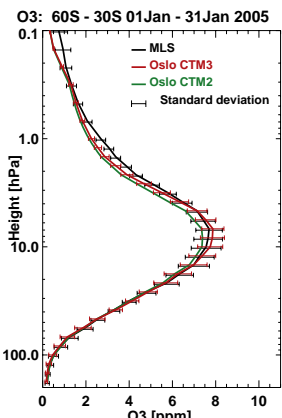

O3: 60S - 30S 01 Jul - 31 Jul 2005

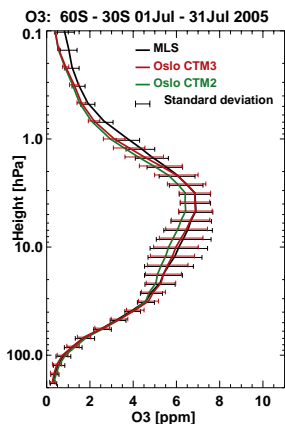

EQ

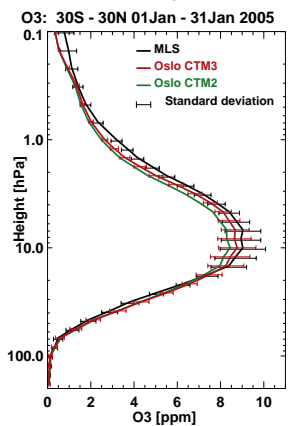

O3: 30S - 30N 01Jul - 31 Jul 2005

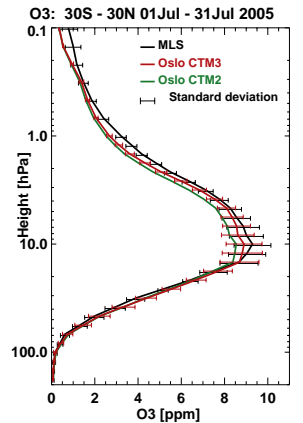

NM

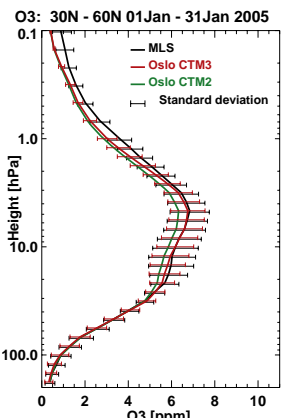

O3: 30N - 60N 01 Jul - 31Jul 2005

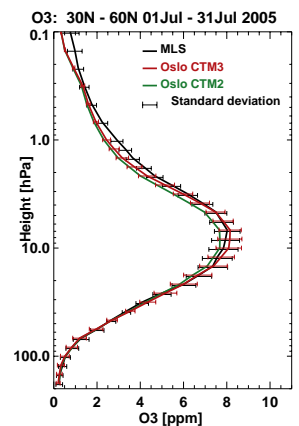

$\mathrm{NH}$

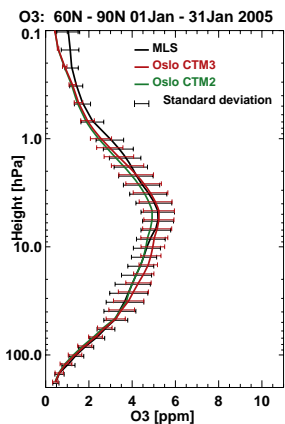

O3: 60N - 90N 01Jul - 31Jul 2005

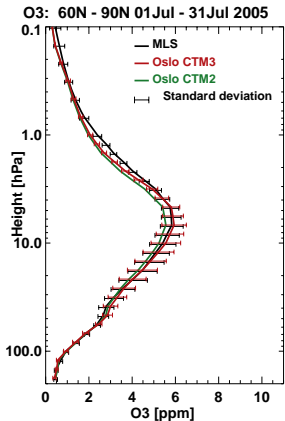

Fig. 7. Comparison of $\mathrm{O}_{3}(\mathbf{a}), \mathrm{HNO}_{3}$ (b), and $\mathrm{N}_{2} \mathrm{O}$ (c) from CTM3 (C3_ssn), CTM2 (C2_ssn) and MLS, as vertical profiles of zonal monthly means covering the latitude bands $90^{\circ} \mathrm{S}-60^{\circ} \mathrm{S}$ (southern high, column "SH"), $60^{\circ} \mathrm{S}-30^{\circ} \mathrm{S}$ (southern mid-lat, column "SM"), $30^{\circ} \mathrm{S}-30^{\circ} \mathrm{N}$ ("EQ"), $30^{\circ} \mathrm{N}-60^{\circ} \mathrm{N}$ ("NM") and $60^{\circ} \mathrm{N}-90^{\circ} \mathrm{N}$ ("NH") for January 2005 and July 2005. Model profiles are processed with the MLS averaging kernel and a-priori profiles.

b.
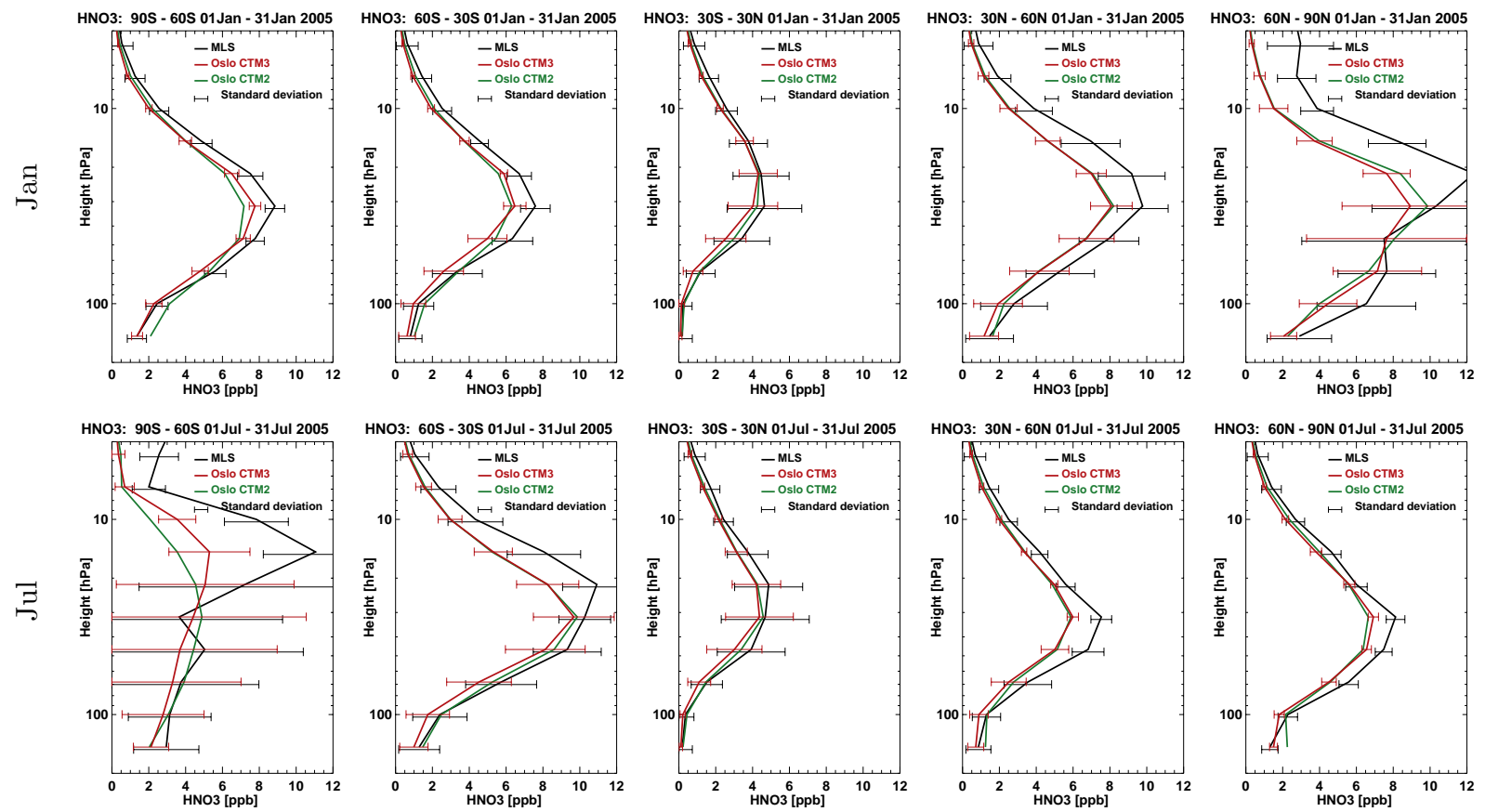

Fig. 7. Continued. 
c.
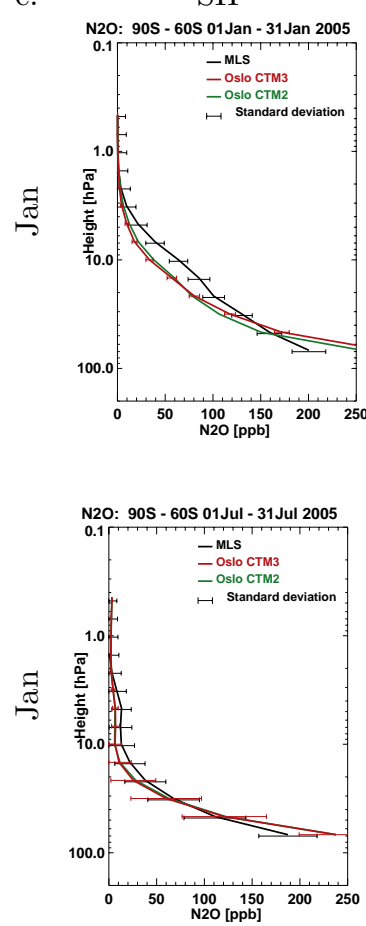

$\mathrm{SM}$
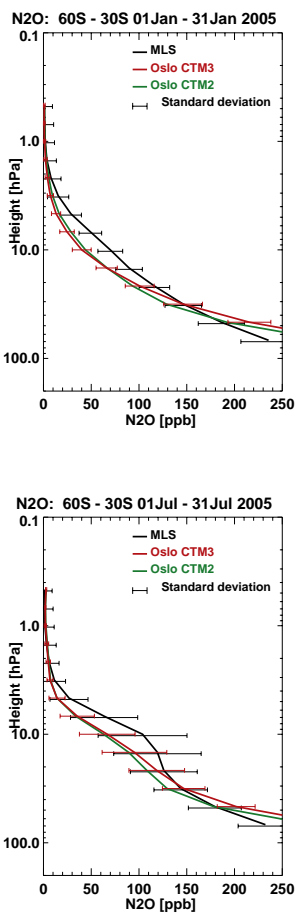

EQ
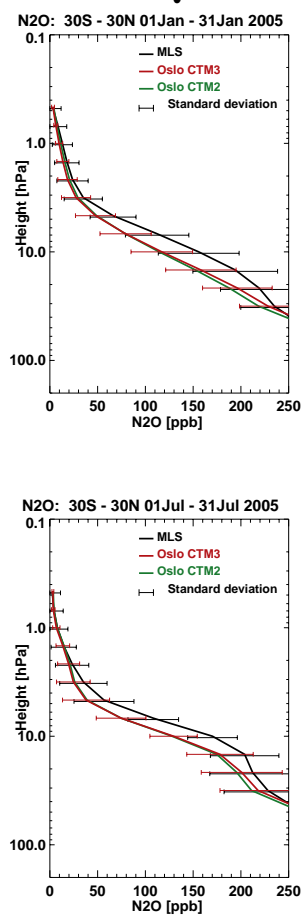

NM
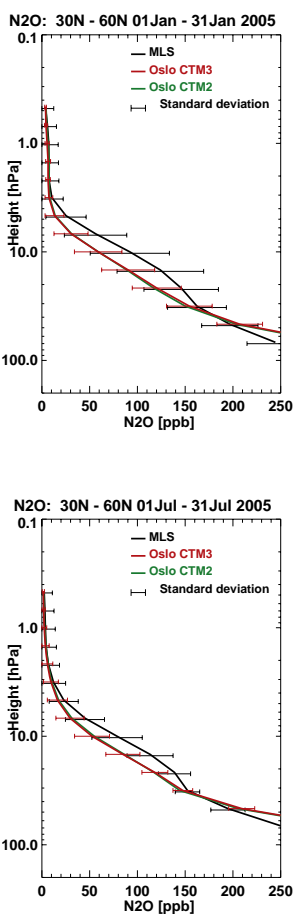

$\mathrm{NH}$

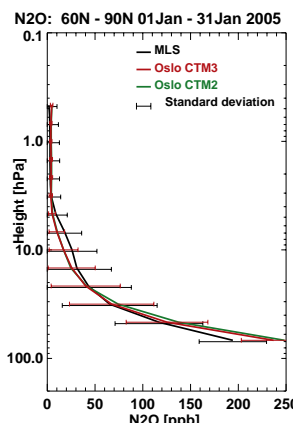

Fig. 7. Continued.

for the same regions as in Hoyle et al. (2011), are shown in Fig. 9, where Oslo CTM3 in general has smaller mixing ratios for T6h than does the CTM2 (up to $100 \%$ difference at 200-100 hPa), and slightly smaller for T20d.

As described in Sect. 2.2.2, the CTM2 only uses updraft convective mass fluxes; convective downdrafts are not taken into account, and neither are detrainment rates into the up- or downdrafts. In Oslo CTM3, downdrafts and detrainment rates are also taken into account, and while downdrafts change the results negligibly (not shown), the use of detrainment rates explains most of the model differences in T6h above 550-300 hPa (dash-dotted lines in Fig. 9). At the surface there are little differences in T6h between CTM3 and CTM2 due to the constantly replenishing to $1 \mathrm{ppm}$ below $500 \mathrm{~m}$. Using the detrainment rates transports substantially less to high altitudes due to venting below, as explained in Sect. 2.2.2. Even though the difference between CTM2 and CTM3 is smaller for T20d than for T6h, skipping downdrafts and detrainments still shifts T20d in CTM3 towards the CTM2 profiles above $700-550 \mathrm{hPa}$.

Hoyle et al. (2011) used a different set of meteorological data, so a direct comparison is not possible. However, from our results we can assume that inclusion of downdrafts and detrainments would shift their Oslo CTM2 towards the FRSGC/UCI results for T6h below $100 \mathrm{hPa}$, while T20d would be shifted closer to the other models.

In general, the Oslo CTM 3 transports up to $\sim 10 \%$ less out of the lowermost model layers than CTM2, mainly in sub- tropical and mid-latitude regions. This may be due to small differences in the boundary layer schemes or in the different treatments of convection.

\subsubsection{Vertical profiles $-\mathrm{O}_{3}$ sondes}

Vertical profiles of $\mathrm{O}_{3}$, interpolated linearly to the location of selected sonde stations around the world, are put out hourly from the models. This allows reasonable temporal interpolations to sonde launch times, thereby giving a better basis for comparing modelled and observed profiles. To evaluate the modelled $\mathrm{O}_{3}$ in the troposphere, we compare the models to $\mathrm{O}_{3}$ sonde measurements available from the World Ozone and Ultraviolet Radiation Data Centre (WOUDC), and also from Southern Hemisphere ADditional OZonesondes (SHADOZ) (Thompson et al., 2003), for the year 2005.

In Fig. 10 we show sonde comparisons for selected stations as monthly means, using model profiles only at measurement times. Observations are in black, CTM3 in red and CTM2 in green. To calculate the means, all profiles for a given month and station have been interpolated to a fixed pressure spacing, i.e. the 60-layer model spacing for a surface pressure of $1000 \mathrm{hPa}$. For each mean profile we show the standard deviation as horizontal bars, and the range of $\mathrm{O}_{3}$ in the observations (backslashed black) and in the Oslo CTM3 profiles (slashed red). We show only the mean for CTM2, as its variation is similar to CTM3. In general, CTM3 produce somewhat better profiles than does 


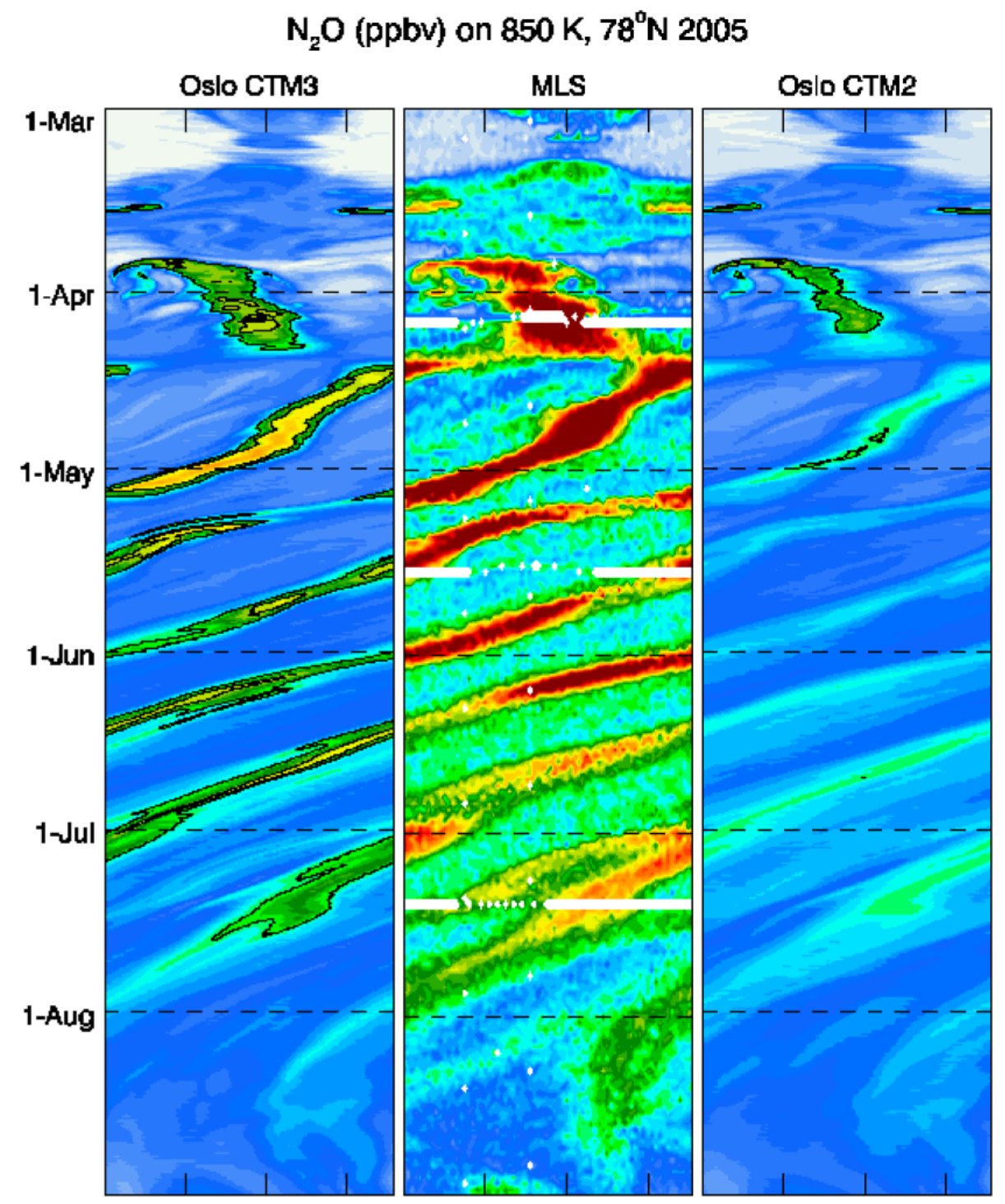

OE $100 \mathrm{E} 200 \mathrm{E}$ 300E OE 100E 200E 300E 0E 100E 200E 300E

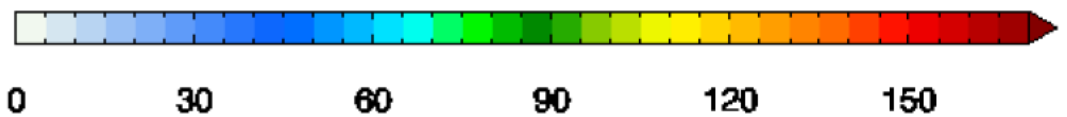

Fig. 8. Hovmöller plot of $\mathrm{N}_{2} \mathrm{O}$ at $850 \mathrm{~K}$ and $78^{\circ} \mathrm{N}$, as modelled by Oslo CTM3 (left), measured by MLS (middle) and modelled by Oslo CTM2 (right). Contours on CTM panels are $75 \mathrm{ppb}$ and $100 \mathrm{ppb}$.

CTM2. In the supplementary material we also include oneto-one comparisons of models and observations for all the single sonde measurements used in the means. From these single sonde profiles, we see that CTM2 sometimes capture tropopause folds better than CTM3. However, shortening the transport time step does improve CTM3 tropopause folds (not shown).

As noted in Sect. 2.5, model emissions are for the year 2000. Therefore we have included a similar comparison for the year 2000 in the Supplement, showing similar model performance as for 2005 .
In general, CTM3 produce slightly better profiles than does CTM2, although for some of the locations and months, CTM2 reproduce measurements better. There are small differences between $\mathrm{C} 3$ _ssn and $\mathrm{C} 3$, and between $\mathrm{C} 2$ _ssn and $\mathrm{C} 2$, mainly in the upper troposphere and lowermost stratosphere; however, the relative differences near the surface may be larger (up to about $25 \%$, not shown). 

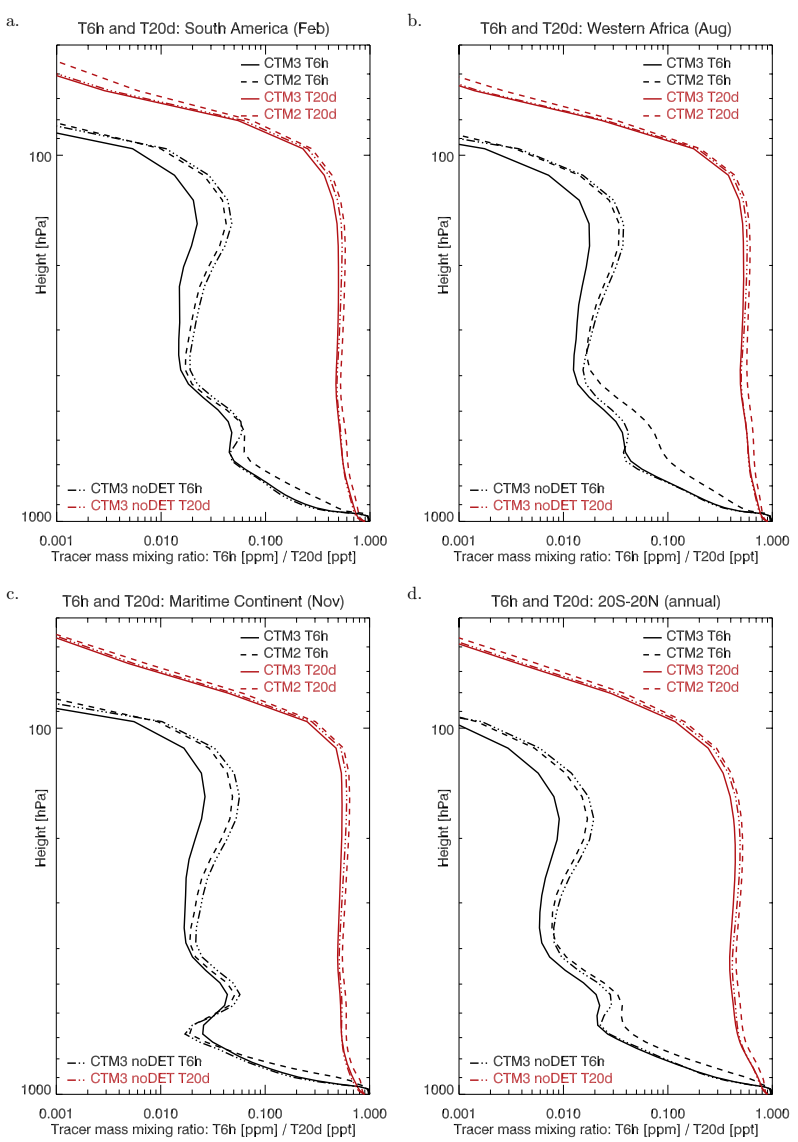

Fig. 9. T6h (ppm) and T20d (ppt) tracer as described in text and by Hoyle et al. (2011): selected monthly means for regions and annual mean for $20^{\circ} \mathrm{S}-20^{\circ} \mathrm{N}$.

\subsubsection{Modelling CARIBIC CO measurements}

The atmospheric abundance of $\mathrm{CO}$ is important for $\mathrm{OH}$. On a global average, we find surface CO in CTM3 to match CTM2. On a monthly basis, CTM3 has a more pronounced seasonal variation, being up to $5 \%$ lower in $\mathrm{NH}$ spring and $5 \%$ higher in NH autumn. As found in Sect. 3.2.2, CTM3 transports less out of the boundary layer, and for $\mathrm{CO}$ we see that CTM3 has up to $50 \%$ higher abundances over land, while having up to $10 \%$ less over ocean. A comparison of modelled and measured CO at Alert station (shown in Supplement) reveals that while CTM 3 is $5-15 \%$ lower than CTM2, both models catch the seasonal variation, but underestimates at $\mathrm{NH}$ winter, as was found in the multi-model CO-comparison of Shindell et al. (2006). A comparison for the Hohenpeißenberg station, shows that CTM3 is on average about $15 \%$ higher than CTM2. Unfortunately, it has not been possible to compare our results directly with CTM2 results from the comparison of Shindell et al. (2006), a study which used different emissions; with slightly higher total amount of $\mathrm{CO}$ emissions, $1077 \mathrm{Tg} \mathrm{yr}^{-1}$ compared to our $1012 \mathrm{Tg} \mathrm{yr}^{-1}$ from RETRO, POET and GFEDv3 datasets.
It can be noted that the anthropogenic emissions in RETRO do have a month-to-month variation, in contrast to the emissions in their study. Shindell et al. (2006) suggest NH emissions are too low, and recently other studies also suggest that CO emissions are low in general (Lamarque et al., 2010; Pison et al., 2009; Kopacz et al., 2010). It should be mentioned that the recent JPL recommendations (Sander et al., 2011) may change the modelled $\mathrm{CO}$, a study which has not been possible in this work.

With our focus on transport differences between CTM2 and CTM3, we look more specifically at the capability of CTM3 to properly incorporate emissions originating from biomass burning, compared to that of CTM2. For this we compare our modelled $\mathrm{CO}$ in the troposphere with measurements carried out in 2005 by CARIBIC (Civil Aircraft for the Regular Investigation of the atmosphere Based on an Instrument Container, http://www.caribic-atmospheric.com, Brenninkmeijer et al., 2007). In the year 2005, most CARIBIC flights were operated between Europe and South America, and model results are interpolated on-line to the spatial and temporal locations of measurements. Figure 11 shows all $\mathrm{CO}$ measurements for all flights in 2005 (black), along with corresponding model output (CTM3 in red, CTM2 in green). Measurements located in the CTM stratosphere (defined in Sect. 3.3) are shown in blue. While observations reached up to $\sim 500 \mathrm{ppb}$, we have cut off the y-axis at $250 \mathrm{ppb}$ to make the figure more readable; all model results are lower than $250 \mathrm{ppb}$. Both CTM2 and CTM3 produce CO remarkably close to measured values. Even though most of the flight measurements are carried out over the Atlantic, spikes originating from biomass burning events in August and October can be seen (Ebinghaus et al., 2007). These events are well modelled, which is due to the combination of realistic meteorological data and that the horizontal distribution of model $\mathrm{CO}$ emissions from biomass burning to a large degree is well represented. It should be noted that recently Hooghiemstra et al. (2012) found that GFEDv3 emissions are too low in South America for the years 2006-2010, which could also be the case for 2005 used in our study. CTM3 produce larger spikes than CTM2 does, due to the improved vertical transport in CTM3. It is expected that with a higher temporal resolution on GFEDv3 emissions, these spikes would be even higher.

\subsection{Global diagnostics}

Several global diagnostics are frequently used to evaluate atmospheric models, such as the $\mathrm{CH}_{4}$ lifetime, the average tropospheric $\mathrm{OH}$ concentration, the $\mathrm{O}_{3}$ burden and the mass flux of $\mathrm{O}_{3}$ from the stratosphere into the troposphere. Here we present these and also the lifetime of $\mathrm{N}_{2} \mathrm{O}$.

The diagnostics are in general calculated within domains between the model surface and four different upper boundaries. These upper boundaries are our model tropopause (2.5 PVU), $200 \mathrm{hPa}$, the $150 \mathrm{ppb} \mathrm{O}_{3}$ surface, and 


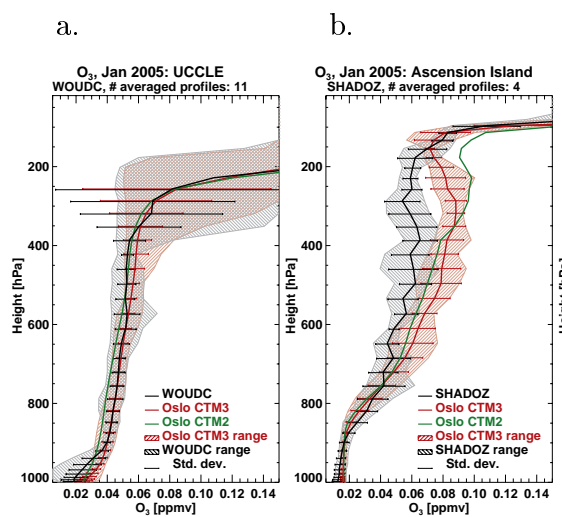

c.
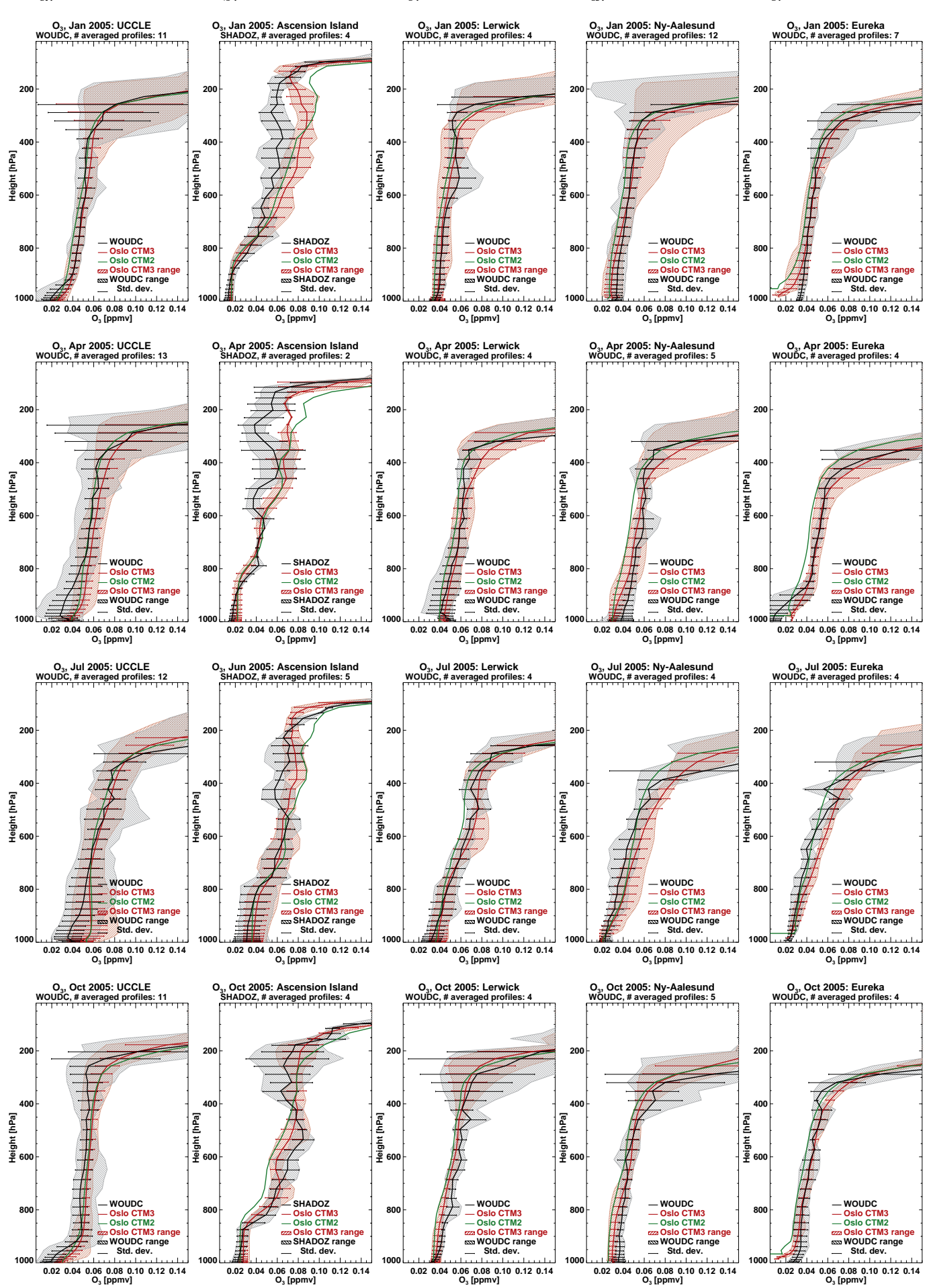

Fig. 10. Modelled (C3_ssn and $\left.\mathrm{C} 2 \_s s n\right)$ and measured monthly mean vertical profiles of $\mathrm{O}_{3}$ at selected sonde stations (a-e) in 2005. Different months for each station are shown in columns.

the model top (LTOP). The prior defines the tropopause at potential vorticity of $2.5 \mathrm{PVU}$ (Holton et al. (1995), 1 PVU is $10^{-6} \mathrm{~K} \mathrm{~m}^{2} \mathrm{~kg}^{-1} \mathrm{~s}^{-1}$ ), with an upper limit of $380 \mathrm{~K}$ poten- tial temperature and a somewhat arbitrary lower limit of $5 \mathrm{~km}$ (only occurs occasionally). For 2005, the fraction of air below the CTM tropopause is $80.2 \%$, while below $200 \mathrm{hPa}$ it 


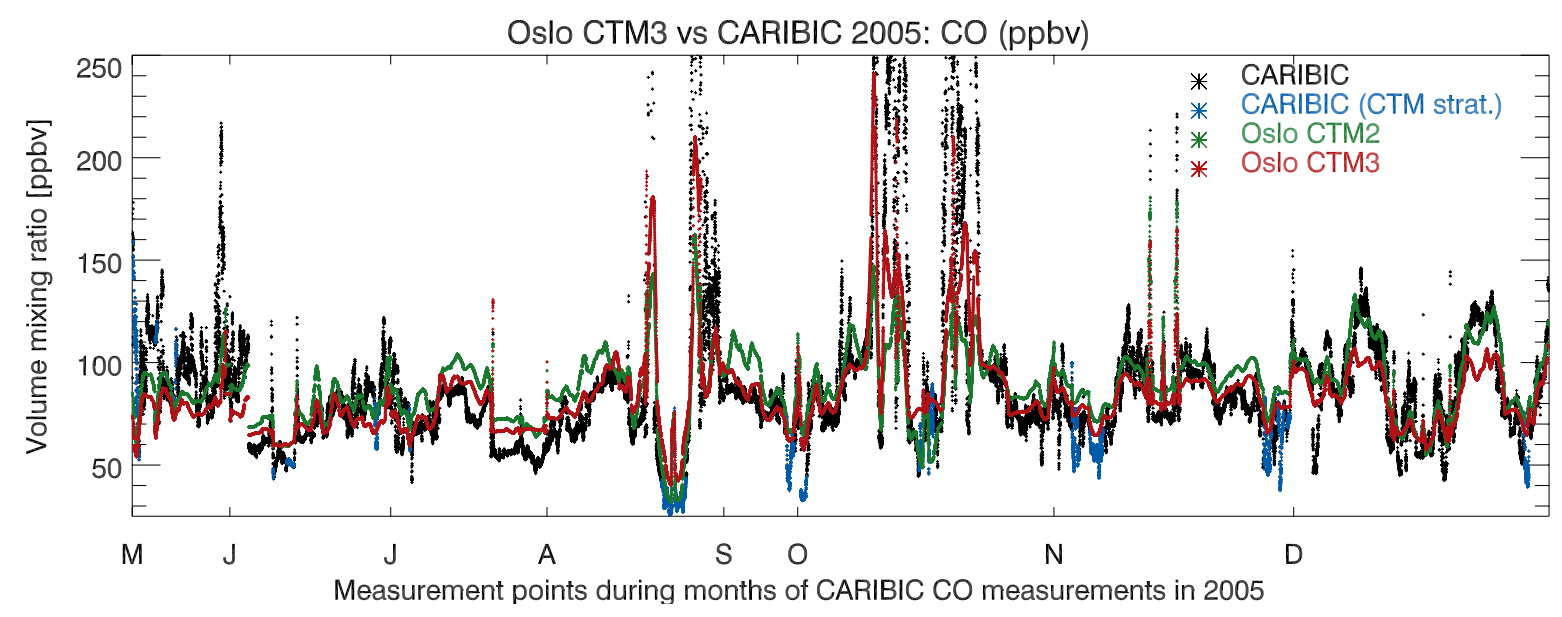

Fig. 11. Oslo CTM3 (red) and CTM2 (green) compared with all CO measurements from CARIBIC flights (black) in 2005, resulting in an asynchronous time axis where only the start of each month is shown. Measurements carried out at locations in the CTM stratosphere (defined by 2.5 PVU) are shown in the blue "CARIBIC (CTM strat.)"

is $79.7 \%$. The fraction below $150 \mathrm{ppb} \mathrm{O}_{3}$, in general higher than 2.5 PVU, differs slightly for the different runs: $84.6 \%$ for $\mathrm{C} 3,85.5 \%$ for $\mathrm{C} 3 \_s s n, 83.4 \%$ for $\mathrm{C} 2$ and $83.5 \%$ for C2_ssn.

\subsubsection{OH concentration}

$\mathrm{OH}$ is the main oxidizing species in the troposphere, driven by photolysis rates. It is usually referred to in context of $\mathrm{CH}_{4}$ lifetime, which will be discussed in Sect. 3.3.2. Here we present average $\mathrm{OH}$ from the different year 2005 simulations, calculated from monthly means of $\mathrm{OH}$, air mass, pressure $(p)$ and temperature $(T)$. Two averaging kernels are used to calculate $\mathrm{OH}$ average; first the $\mathrm{OH}$ concentration is weighted by air mass and by the loss rate to $\mathrm{CH}_{4}(\exp (-1775 / T))$, and second it is weighted by air mass and a simplified loss rate of $\mathrm{CO}$ using pressure $(1+0.6 p)$. The values are presented in Table 3, showing small differences for the different model domains.

In simulation $\mathrm{C} 3$, the annual mean $\mathrm{CH}_{4}$-loss weighted $\mathrm{OH}$ concentration is $\sim 1.55 \times 10^{6} \mathrm{molec} \mathrm{cm}^{-3}$, while in $\mathrm{C} 2$ it is $\sim 1.35 \times 10^{6} \mathrm{molec} \mathrm{cm}^{-3}$. C3_ssn and C2_ssn produce values of $\sim 1.39 \times 10^{6} \mathrm{molec}^{-3}$ and $\sim 1.22 \times 10^{6}$ molec $\mathrm{cm}^{-3}$, respectively. For the $\mathrm{OH}$ average weighted against $(1+0.6 p)$, the averages are about $10 \%$ smaller, but otherwise show the similar picture. We find that the vertical distribution of lightning to a fixed height of $16 \mathrm{~km}$, as in CTM2 (Sect. 2.6), can explain about $50 \%$ of the larger OH in CTM3 compared to CTM2. Otherwise, the increase is partly due to updates in solar fluxes and $\mathrm{O}\left({ }^{1} \mathrm{D}\right)$ quantum yields (Hsu and Prather, 2009) and to differences in wet scavenging. The latter will affect $\mathrm{OH}$ through scavenging of, e.g., $\mathrm{HNO}_{3}$ and $\mathrm{H}_{2} \mathrm{O}_{2}$, and will be addressed in Sect. 3.4.
Inclusion of sulfur and nitrate modules in CTM2 and CTM3 is important for $\mathrm{OH}$, reducing it by $10-11 \%$. As already noted, conversion of $\mathrm{N}_{2} \mathrm{O}_{5}$ to $\mathrm{HNO}_{3}$ on aerosols is included in the tropospheric chemistry scheme; it is the same in CTM3 and CTM2, and cannot explain the reduction in $\mathrm{OH}$. From a 3-yr simulation (1997-1999) where nitrate aerosols are excluded, we find that about $50 \%$ of the reduced $\mathrm{OH}$ may be due to sulfur chemistry removing $\mathrm{OH}$ through oxidation processes. As important is the sequestering of $\mathrm{NO}_{\mathrm{x}}$ in nitrate aerosols (Myhre et al., 2006), which with subsequent washout adds a removal process of atmospheric nitrogen and thus a source of $\mathrm{OH}$. $\mathrm{OH}$ reduction due to the nitrate module is most pronounced in $\mathrm{NH}$ winter/spring, when the winddriven production of sea salt is largest.

Lamarque et al. (2010) showed that the RETRO anthropogenic $\mathrm{CO}$ emissions are probably too low, and other studies indicate that estimated $\mathrm{CO}$ emissions probably are too low in general (Pison et al., 2009; Kopacz et al., 2010). However, when increasing the anthropogenic $\mathrm{CO}$ emissions by $20 \%$ in CTM3, we find $<1 \%$ reduction in the $\mathrm{OH}$ numbers. Locally, the accompanying effect on $\mathrm{O}_{3}$ can be large (up to $100 \%$ ), but in the zonal mean $\mathrm{O}_{3}$ increases by less than $1 \%$. Even though the RETRO emissions may be low on $\mathrm{CO}, \mathrm{OH}$ is not very sensitive to an increase in anthropogenic emissions.

Further, fast-JX allows for letting aerosols affect photochemistry through scattering and absorption, thereby possibly changing $\mathrm{OH}$. Bian et al. (2003) found the effect of aerosols on photolysis to reduce global $\mathrm{OH}$ by $\sim 8 \%$, similar to Martin et al. (2003) who also found a larger reduction in the Northern Hemisphere than in the Southern Hemisphere. This will be investigated in the already-mentioned upcoming CTM3 paper focusing on aerosols. 
Table 3. Annual average of $\mathrm{OH}$ in the atmosphere, calculated from monthly means of $\mathrm{OH}$, air mass, temperature $(T)$ and pressure $(p$, in bars), for the air mass below the model PVU-based tropopause height, air mass below $200 \mathrm{hPa}$, air mass below the modelled 150 ppb $\mathrm{O}_{3}$ surface, and the air mass in the whole model domain (up to top level LTOP). The average OH concentration is weighted by air mass and by (a) the loss rate of $\mathrm{CH}_{4}(\exp (-1775 / T))$ and (b) the approximate loss rate of $\mathrm{CO}(1+0.6 p)$. All numbers are for the year 2005 , and the ranges of monthly means are given in parentheses.

\begin{tabular}{lcccc}
\hline $\begin{array}{l}\text { a. }[\mathrm{OH}] \\
\text { Diagnosed between surface and selected upper boundaries. }\end{array}$ & \\
\hline Sim. & $2.5 \mathrm{PVU}$ & $200 \mathrm{hPa}$ & $150 \mathrm{ppb} \mathrm{O}_{3}$ & LTOP \\
\hline $\mathrm{C} 3$ & $1.55(1.47-1.70)$ & $1.54(1.46-1.70)$ & $1.54(1.46-1.70)$ & $1.55(1.47-1.69)$ \\
$\mathrm{C} 3 \_s s n$ & $1.39(1.30-1.56)$ & $1.38(1.29-1.56)$ & $1.38(1.29-1.56)$ & $1.39(1.31-1.56)$ \\
$\mathrm{C} 2$ & $1.35(1.27-1.49)$ & $1.34(1.26-1.48)$ & $1.35(1.26-1.48)$ & $1.35(1.28-1.48)$ \\
C2_ssn & $1.22(1.11-1.36)$ & $1.21(1.11-1.36)$ & $1.21(1.11-1.36)$ & $1.22(1.13-1.37)$ \\
\hline b. [OH] & $\left(10^{6}\right.$ molec cm $\left.{ }^{-3}\right)$ weighted by air mass and $(1+0.6 p)$. & \\
Diagnosed between surface and selected upper boundaries. & \\
\hline Sim. & $2.5 \mathrm{PVU}$ & $200 \mathrm{hPa}$ & $150 \mathrm{ppb} \mathrm{O}_{3}$ & LTOP \\
\hline C3 & $1.40(1.33-1.54)$ & $1.39(1.32-1.53)$ & $1.39(1.32-1.53)$ & $1.37(1.30-1.50)$ \\
C3_ssn & $1.26(1.16-1.41)$ & $1.24(1.15-1.40)$ & $1.25(1.16-1.40)$ & $1.23(1.14-1.38)$ \\
C2 & $1.21(1.13-1.34)$ & $1.20(1.12-1.32)$ & $1.21(1.13-1.33)$ & $1.18(1.11-1.31)$ \\
C2_ssn & $1.09(0.99-1.23)$ & $1.07(0.97-1.21)$ & $1.08(0.98-1.22)$ & $1.06(0.97-1.20)$ \\
\hline
\end{tabular}

Table 4. Annual average lifetimes of $\mathrm{CH}_{4}\left(\tau_{\mathrm{CH}_{4}}\right)$, diagnosed as the total $\mathrm{CH}_{4}$ burden (surface to model top) divided by the loss of $\mathrm{CH}_{4}$ within the four diagnosed domains: below the model PVU-based tropopause height, below $200 \mathrm{hPa}$ surface, below the modelled $150 \mathrm{ppb} \mathrm{O}_{3}$ surface, and the whole model domain (up to top level LTOP). All numbers are for the year 2005, and the ranges of monthly means are given in parentheses.

\begin{tabular}{lcccc}
\hline \multicolumn{5}{l}{$\tau_{\mathrm{CH}_{4}}(\mathrm{yr})$. Diagnosed between surface and selected upper boundaries. } \\
Sim. & $2.5 \mathrm{PVU}$ & $200 \mathrm{hPa}$ & $150 \mathrm{ppb} \mathrm{O}_{3}$ & LTOP \\
\hline $\mathrm{C} 3$ & $7.98(6.96-8.62)$ & $8.03(7.02-8.67)$ & $7.94(6.94-8.56)$ & $7.55(6.64-8.11)$ \\
$\mathrm{C} 3 \_s s n$ & $8.86(7.59-8.83)$ & $8.89(7.63-9.85)$ & $8.81(7.56-9.75)$ & $8.33(7.22-9.16)$ \\
$\mathrm{C} 2$ & $9.18(7.98-10.06)$ & $9.26(8.06-10.15)$ & $9.14(7.95-10.01)$ & $8.64(7.59-9.39)$ \\
$\mathrm{C} 2 \_s s n$ & $10.20(8.68-11.43)$ & $10.31(8.77-11.55)$ & $10.16(8.65-11.37)$ & $9.54(8.22-10.58)$ \\
\hline
\end{tabular}

\subsection{2 $\quad \mathrm{CH}_{4}$ and $\mathrm{N}_{2} \mathrm{O}$ lifetimes}

The main atmospheric sink of the greenhouse gas $\mathrm{CH}_{4}$ is $\mathrm{OH}$, predominantly in the troposphere. $\mathrm{CH}_{4}$ is also lost to $\mathrm{Cl}$ and $\mathrm{O}\left({ }^{1} \mathrm{D}\right)$, mainly in the stratosphere, with small additional loss to $\mathrm{Cl}$ in the marine boundary layer. In the troposphere, CTM2 and CTM3 neglect $\mathrm{Cl}$ chemistry and also the $\mathrm{CH}_{4}$ loss to $\mathrm{O}\left({ }^{1} \mathrm{D}\right)$. Instead of simulating surface emissions and soil uptake, both models use prescribed surface concentrations of $\mathrm{CH}_{4}$, based on CTM2 simulations with $\mathrm{CH}_{4}$ emissions and surface deposition (HYMN-report, 2010).

Table 4 lists global mean $\mathrm{CH}_{4}$ lifetimes in 2005, calculated from monthly mean total $\mathrm{CH}_{4}$ burden and cumulative monthly $\mathrm{CH}_{4}$ loss. On a monthly basis, $\mathrm{CH}_{4}$ lifetime is shortest during $\mathrm{NH}$ summer, consistent with the seasonal cycle of $\mathrm{OH}$. Our three tropospheric definitions produce lifetimes that differ by up to $10 \%$, with the shortest lifetimes estimated using the $150 \mathrm{ppb} \mathrm{O}_{3}$ boundary because it includes the tropical upper troposphere and some high latitude stratospheric loss due to $\mathrm{Cl}$ and $\mathrm{O}\left({ }^{1} \mathrm{D}\right)$. We use the $\mathrm{O}_{3}$-based tropopause definition in this section.

The tropospheric $\mathrm{CH}_{4}$ lifetime in CTM3 is $7.9 \mathrm{yr}$, versus $9.1 \mathrm{yr}$ in CTM2, consistent with the larger $\mathrm{OH}$ concentration in the updated model. Adding sulfur and nitrate aerosols increases the lifetime by $\sim 12 \%$, to $8.9 \mathrm{yr}$ in CTM3 (sim. C3_ssn). This aerosol effect is slightly smaller in CTM2 $(\sim 11 \%)$. Past studies have found a similar impact of aerosols on $\mathrm{CH}_{4}$ lifetime via surface reactions (Martin et al., 2003; Macintyre and Evans, 2010). Recent evaluation of the $\mathrm{CH}_{4}$ lifetime (Prather et al., 2012), total and against loss by tropospheric $\mathrm{OH}$, take into account the recently observed $\mathrm{CH}_{3} \mathrm{CCl}_{3}$ decay (Montzka et al., 2011) and up-to-date estimates with uncertainties of the other factors that go into the lifetime calculation. Prather et al. (2012) report the $\mathrm{CH}_{4}$ lifetime with respect to tropospheric $\mathrm{OH}$ (the so-called tropospheric $\mathrm{OH}$-lifetime) to be $11.2 \pm 1.3 \mathrm{yr}$, which is longer than earlier estimates of $(8.7 \pm 1.3 \mathrm{yr}$ IPCC AR4, 2007). Thus, the tropospheric $\mathrm{OH}$-lifetime of $\mathrm{CH}_{4}$ in $\mathrm{CTM} 3$, when including 
Table 5. Modelled annual average $\mathrm{O}_{3}$ burden $\left[\mathrm{Tg}\left(\mathrm{O}_{3}\right)\right]$ for different definitions of tropospheric domains.

\begin{tabular}{lcccccc}
\hline & \multicolumn{5}{c}{ Diagnosed between surface and a selection of upper boundaries. } \\
Simulation & 2005 & $1998-2005$ & 2005 & $1998-2005$ & 2005 & $1998-2005$ \\
\hline C3 & $360(340-386)$ & 360 & $356(342-374)$ & 357 & $391(373-415)$ & 390 \\
C3_ssn & $331(310-359)$ & 331 & $344(327-361)$ & 345 & $363(344-388)$ & 362 \\
C2 & $352(336-376)$ & 354 & $344(331-355)$ & 347 & $372(358-389)$ & 373 \\
C2_ssn & $326(309-352)$ & 328 & $317(303-331)$ & 321 & $346(332-366)$ & 347 \\
\hline
\end{tabular}

aerosols, is shorter than the recent estimate, but within the range of older estimates. Adding aerosols to the photolysis calculation, currently neglected in CTM2 and CTM3, could increase the tropospheric-OH lifetime by $\sim 8 \%$ (Bian et al., 2003; Martin et al., 2003) to $\sim 10 \mathrm{yr}$ in CTM3 and bring CTM3 within the recent methyl chloroform constraint.

Over the entire atmosphere, the $\mathrm{CH}_{4}$ lifetime due to all chemical losses is $9.5 \mathrm{yr}$ in CTM2 and $8.4 \mathrm{yr}$ in CTM3 in the simulations with aerosols. If we include estimates of the soil and tropospheric $\mathrm{Cl}$ sinks (Prather et al., 2012), the total lifetimes decrease 7-10\%. Because the CTMs use prescribed surface $\mathrm{CH}_{4}$ concentrations, but have different $\mathrm{CH}_{4}$ lifetimes, they calculate different $\mathrm{CH}_{4}$ burdens. These are $4830 \mathrm{Tg}$ and $4822 \mathrm{Tg}$ for simulations $\mathrm{C} 2$ and $\mathrm{C} 3$, respectively (4831 Tg and $4825 \mathrm{Tg}$ for C2_ssn and C3_ssn, respectively). All are about $2 \%$ lower than the burden estimated by IPCC (4932 Tg, IPCC AR4, 2007). The stratospheric lifetime of $\mathrm{CH}_{4}$ is $147 \mathrm{yr}$ and $141 \mathrm{yr}$ in CTM2 and CTM3, respectively. These lifetimes change only slightly $(<3 \%)$ after including tropospheric aerosols. We estimate that $\mathrm{OH}, \mathrm{Cl}$, and $\mathrm{O}\left({ }^{1} \mathrm{D}\right)$ cause $47 \%, 29 \%$ and $24 \%$ of stratospheric $\mathrm{CH}_{4}$ oxidation, respectively.

Another important greenhouse gas is $\mathrm{N}_{2} \mathrm{O}$, which in general is inert in the troposphere, while having a small stratospheric loss. Hence, $\mathrm{N}_{2} \mathrm{O}$ has a long lifetime, and in CTM3 we calculate it to be $144 \mathrm{yr}$, with a monthly average range of 133-155 yr. Because the photolysis code used in CTM2 (fast-J2) had smaller solar fluxes in the $200-230 \mathrm{~nm}$ region where $\mathrm{N}_{2} \mathrm{O}$ and $\mathrm{O}_{2}$ are photolyzed in most of the stratosphere, the $\mathrm{N}_{2} \mathrm{O}$ lifetime in CTM2 is longer, $151 \mathrm{yr}$. It is worth noting that the CTM2 and CTM3 keep $\mathrm{N}_{2} \mathrm{O}$ fixed at the surface and at the uppermost model layer - with the same mixing ratios in both models. The $\mathrm{N}_{2} \mathrm{O}$ lifetimes are probably too long because of slow vertical transport in the cycle 36r1 meteorology used in both calculations, somewhat evident in the underestimate of the $\mathrm{CTM} \mathrm{N}_{2} \mathrm{O}$ profiles (Fig. 7).

\subsection{3 $\mathrm{O}_{3}$ burden}

We have calculated the tropospheric burden of $\mathrm{O}_{3}$ using the tropospheric domains defined in Sect. 3.3.2. The numbers are presented in Table 5 for the year 2005, and as the mean of years 1998 to 2005. Also, the ranges of the monthly mean values for 2005 are listed. The interannual variation is small, as are the differences between CTM3 and CTM2. Below the $150 \mathrm{ppb} \mathrm{O}_{3}$ surface, modelled burden in 2005 is $391 \mathrm{Tg}$ for $\mathrm{C} 3$ and $363 \mathrm{Tg}$ for C3_ssn, while the Oslo CTM2 produces $372 \mathrm{Tg}$ for $\mathrm{C} 2$ and $346 \mathrm{Tg}$ for C2_ssn. Similar values are found for the 1998-2005 averages. Within the domains below our model tropopause and below $200 \mathrm{hPa}$, which are smaller domains, the $\mathrm{O}_{3}$ burden is $5-10 \%$ lower than when using the $150 \mathrm{ppb} \mathrm{O}_{3}$ definition. Based on several model studies, Stevenson et al. (2006) presented a tropospheric burden range of $344 \pm 39 \mathrm{Tg}$, calculated from all air masses with $\mathrm{O}_{3}$ less than $150 \mathrm{ppb}$. The $\mathrm{C} 3$ sssn and $\mathrm{C} 2$ sssn runs lie well within this range, with values of 346 and $363 \mathrm{Tg}$, respectively. When excluding the aerosols our models lie in or just above the upper end of the range. It should be noted that Stevenson et al. (2006) used different emissions, which could somewhat affect the comparison.

By distributing $\mathrm{L}^{-\mathrm{NO}_{\mathrm{x}}}$ vertically to a fixed altitude of $16 \mathrm{~km}$ in the CTM3, we find that the higher burden in CTM3 compared to CTM2 is most likely due to the differences in $\mathrm{L}-\mathrm{NO}_{\mathrm{x}}$ vertical scaling. Otherwise, as noted in Sect. 3.3.2, the main differences between CTM2 and CTM3 are due to the new fast-JX photochemistry being somewhat more active, and differences in wet scavenging. While this produces higher $\mathrm{O}_{3}$ burden in CTM3, it does not change the relative effect of nitrate aerosols when compared to CTM2, about $8 \%$. A halving of the operator-split time step (C3_1/2) only changes the burden by $\sim 2 \%$, indicating that the tropospheric $\mathrm{O}_{3}$ burden is not very sensitive to the operator-split time step.

\subsubsection{Cross-tropopause $\mathrm{O}_{3}$ flux}

The stratosphere to troposphere exchange (STE) is the net flux from the stratosphere into the troposphere, and is estimated based on observations to be $540 \pm 140 \mathrm{Tg}\left(\mathrm{O}_{3}\right) \mathrm{yr}^{-1}$ (Murphy and Fahey, 1994; Gettelman et al., 1997; IPCC AR4, 2007). Model studies suggest STE around $500 \mathrm{Tg}\left(\mathrm{O}_{3}\right) \mathrm{yr}^{-1}$ (McLinden et al., 2000; Olsen et al., 2001; Hsu et al., 2005), and Stevenson et al. (2006) reported a model range of $552 \pm 168 \mathrm{Tg}\left(\mathrm{O}_{3}\right) \mathrm{yr}^{-1}$.

In Oslo CTM3 the STE calculation follows Hsu et al. (2005), which is the same method as used by Stevenson et al. (2006) (referred to as S2006 below). Due to technical challenges, this has not been possible in CTM2, and while 
Søvde et al. (2011a) presented CTM2 STE, their method is not comparable to the CTM3 treatment - hence we present only CTM3 in this study. During a certain time period in CTM3 (e.g., a month), STE of $\mathrm{O}_{3}$ is calculated as a residual of column mass budgets between the model surface and a certain $\mathrm{O}_{3}$ isopleth (Hsu et al., 2005). Below the given $\mathrm{O}_{3}$ isopleth and for the given time period, this can be written

$$
\left(\frac{\mathrm{d} M}{\mathrm{~d} t}\right)_{\text {tot }}=\left(\frac{\mathrm{d} M}{\mathrm{~d} t}\right)_{\mathrm{chem}}-\mathrm{S}+F_{S \rightarrow t}-F_{h, t \rightarrow t},
$$

where $\left(\frac{\mathrm{d} M}{\mathrm{~d} t}\right)_{\text {tot }}$ is the total change in $\mathrm{O}_{3},\left(\frac{\mathrm{d} M}{\mathrm{~d} t}\right)_{\text {chem }}$ is the corresponding chemical tendency of $\mathrm{O}_{3}$ (corresponding to $\mathrm{P}-\mathrm{L}$ in $\mathrm{S} 2006$ ), $\mathrm{S}$ is sink processes such as dry deposition at the surface and wet scavenging (D in S2006), $F_{h, t \rightarrow t}$ is the horizontal flux of $\mathrm{O}_{3}$ out of the column (troposphere to troposphere), and $F_{s \rightarrow t}$ is the STE to be inferred (both horizontal and vertical). Hence, the left-hand side of Eq. (7) is diagnosed as the change from the beginning to the end of the diagnosed time period, while the right-hand side terms are summed up for all time steps during the time period. S2006 assumed no tropospheric trend, i.e. $\left(\frac{\mathrm{d} M}{\mathrm{~d} t}\right)_{\text {tot }}+F_{h, t \rightarrow t}=0$ in Eq. (7).

We have found the $150 \mathrm{ppb}$ isopleth of $\mathrm{O}_{3}$ used in $\mathrm{S} 2006$ to confuse stratospheric air with tropospheric air for $\mathrm{O}_{3}$-hole conditions, hence we have lowered this isopleth to $120 \mathrm{ppb}$ to minimise this problem. For the year 2005, Oslo CTM3 produce an annual STE of $296 \mathrm{Tg}\left(\mathrm{O}_{3}\right) \mathrm{yr}^{-1}$ for $\mathrm{C} 3$ and $300 \mathrm{Tg}\left(\mathrm{O}_{3}\right) \mathrm{yr}^{-1}$ for $\mathrm{C} 3 \_s s n$. The aerosol included in the ssnruns are not calculated in the stratosphere, but changes the $120 \mathrm{ppb}$ isopleth slightly, thereby changing STE slightly. On a monthly basis, the STE is largest in NH summer, while smallest in NH winter. In an atmosphere without polar stratospheric clouds (PSCs), the $120 \mathrm{ppb}$ isopleth can be very different than when PSCs are included, and stratopsheric burden of $\mathrm{O}_{3}$ is higher. Hsu and Prather (2009) found PSCs to reduce STE by $97 \mathrm{Tg}\left(\mathrm{O}_{3}\right) \mathrm{yr}^{-1}$, and when testing this in CTM3 we find the STE to increase by a comparable amount to $427 \mathrm{Tg}\left(\mathrm{O}_{3}\right) \mathrm{yr}^{-1}$ for the year 2005 . It may be that STE inferred from observations does not fully take the $\mathrm{PSC}^{-\mathrm{O}_{3}}$ hole into account, so modelled STE without PSCs provide insight into this. However, it should be kept in mind that the $120 \mathrm{ppb}$ isopleth has changed.

With the C3_1/2 simulation, STE is slightly reduced to $288 \mathrm{Tg}\left(\mathrm{O}_{3}\right) \mathrm{yr}^{-1}$, due to a slightly changing $\mathrm{O}_{3}$ isopleth and less overshooting of the stratospheric jet. We have also carried out a 14 month simulation starting on 1 November 2004, using an older cycle of the ECMWF IFS meteorology (cycle 29). With this, the Oslo CTM3 produce a STE of $353 \mathrm{Tg}\left(\mathrm{O}_{3}\right) \mathrm{yr}^{-1}$. While this higher flux indicates that the old cycle may provide a more realistic circulation, it should be noted that the $\mathrm{N}_{2} \mathrm{O}$ FrIAC presented in Sect. 3.1.3 is much less pronounced for cycle 29 meteorological data, indicating that cycle 29 polar cap winds are less representative. Still, our comparison with MLS indicates that cycle $36 \mathrm{r} 1$ may have too slow Brewer-Dobson circulation, which will give too low STE. Also, UCI-CTM calculations of STE (Hsu and Prather, 2009) are considerably reduced when using cycle 36r1.

Due to the difficulties with a calculated $\mathrm{O}_{3}$ isopleth, such as stratospheric air being counted as tropospheric air for low $\mathrm{O}_{3}$ and tropospheric $\mathrm{O}_{3}$-rich air in polluted areas being counted as stratospheric air, we have also tested calculating STE through an alternative surface, namely the troposphere defined by the artificial e90-tracer (Prather et al., 2011). With this we find the annual STE of $285 \mathrm{Tg}\left(\mathrm{O}_{3}\right) \mathrm{yr}^{-1}$ for C3_ssn close to the value from using the $120 \mathrm{ppb}$ isopleth. Also, the reduction when halving the operator-split time step is similar to what was found using the $120 \mathrm{ppb}$ isopleth.

\subsection{Wet scavenging}

Wet removal of atmospheric $\mathrm{HNO}_{3}$ and $\mathrm{H}_{2} \mathrm{O}_{2}$ is important for the $\mathrm{NO}_{\mathrm{x}}$ and $\mathrm{OH}$ abundances. Less removal of $\mathrm{H}_{2} \mathrm{O}_{2}$ will increase tropospheric $\mathrm{OH}$, and less removal of $\mathrm{HNO}_{3}$ will increase atmospheric $\mathrm{NO}_{\mathrm{x}} \cdot \mathrm{HNO}_{3}$ can be recycled back to $\mathrm{NO}_{\mathrm{x}}$ by either photodissociation or reaction with $\mathrm{OH}$, but most of it is lost to the surface by wet or dry scavenging. In addition, $\mathrm{NO}_{\mathrm{x}}$ will by itself change $\mathrm{OH}$ by shifting the $\mathrm{HO}_{2} / \mathrm{OH}$ balance.

Hence, if CTM3 wet scavenging is less efficient than for CTM2, the amount of $\mathrm{OH}$ and $\mathrm{NO}_{\mathrm{x}}$ will be higher than in CTM2. Due to the complexity of the coupled system, it has not been possible to separate out the contributions to $\mathrm{OH}$ from increased $\mathrm{NO}_{\mathrm{x}}$ due to the wet scavenging scheme from that due to the update to fast-JX. It should be noted that a major difference from CTM2 to CTM3 scavenging is that CTM2 treats all large-scale precipitation as liquid rain, while CTM3 separates it into ice and liquid precipitation. The only species removed by ice in CTM3 is $\mathrm{HNO}_{3}$, and even that is reduced relative to liquid rain (CTM2). The convective scavenging scheme is the same in both, and treats all convective precipitation as convective rain.

To compare the wet scavenging in CTM3 to CTM2, we have carried out idealised 7-day simulations with only transport and wet removal of $\mathrm{HNO}_{3}$ and $\mathrm{H}_{2} \mathrm{O}_{2}$. Tracer removals by large-scale and convective precipitation are diagnosed hourly. We present results for 1-7 January 2005, but find similar results for other months. The idealised tracers are initialised from the C3_ssn simulation at 1 January 2005.

In the upper troposphere, CTM3 scavenges less by rain than CTM2, while in the lower tropical troposphere, more is scavenged in CTM3. In total $\mathrm{HNO}_{3}$ burden, CTM3 removes less $\mathrm{HNO}_{3}$ than does CTM2; starting from a tropospheric burden of $1.43 \mathrm{Tg}\left(\mathrm{HNO}_{3}\right), \mathrm{CTM} 3$ ends at $0.62 \mathrm{Tg}\left(\mathrm{HNO}_{3}\right)$ after 7 days, while CTM2 ends at $0.40 \mathrm{Tg}\left(\mathrm{HNO}_{3}\right)$. The higher $\mathrm{HNO}_{3}$ in CTM3 is due to large-scale precipitation being constrained by cloud fraction and hence less effective; the amount removed at each time step is about 30 to $40 \%$ lower than for CTM2. Large changes in the initial scavenging rate occur because the initialized fields (C3_ssn) were 
inconsistent with the rapid large-scale scavenging in the upper troposphere by CTM2. By looking at the decay rates over the last few days of the experiment, when the $\mathrm{HNO}_{3}$ distribution more closely matches each CTM's pattern of scavenging, we find that for CTM3 the effective tropospheric lifetime of $\mathrm{HNO}_{3}$ is 9.3 days and for CTM2 it is 6.9 days, confirming the more rapid loss in CTM2. Spatially we find that CTM3 removes less in the upper troposphere, while removing slightly more in the lowermost tropical troposphere, similar to results in Neu and Prather (2012).

The amount removed by convective scavenging is initially similar in CTM2 and CTM3, however, after a few time steps CTM3 removes more by convective scavenging than CTM2, compensating for the reduced large-scale scavenging. However, the fraction of tropospheric $\mathrm{HNO}_{3}$ washed out by convective rain at each time step remains similar in CTM2 and CTM3, since the process is unchanged in the CTM update.

Less effective wet scavenging is also found for $\mathrm{H}_{2} \mathrm{O}_{2}$ in CTM3. The tropospheric $\mathrm{H}_{2} \mathrm{O}_{2}$ burden starts at $3.86 \mathrm{Tg}$, and after 7 days of only transport and wet scavenging, CTM3 ends at $1.66 \mathrm{Tg}$, while CTM2 ends at $0.95 \mathrm{Tg}$. After 7 days these correspond to a tropospheric lifetime of 5.9 days for CTM2 and 11.4 days for CTM3. Initially, CTM2 removes about 4 times as much as CTM3 in large-scale scavenging, which is a larger difference than for $\mathrm{HNO}_{3}$, because $\mathrm{H}_{2} \mathrm{O}_{2}$ is not removed by ice in CTM3 but is removed in CTM2. The fraction of the tropospheric burden removed by convective scavenging is smaller in CTM3, which was not the case for $\mathrm{HNO}_{3}$. While Neu and Prather (2012) found $\mathrm{H}_{2} \mathrm{O}_{2}$ uptake in ice to have a very small effect on $\mathrm{O}_{3}$, the differences from CTM2 to CTM3 may be large enough to re-examine this result.

Our chemistry simulations $\mathrm{C} 2$ and $\mathrm{C} 3$ show similar results; less $\mathrm{HNO}_{3}$ is scavenged in CTM3, giving the latter a higher tropospheric burden of $\mathrm{HNO}_{3}$. The very different pattern of scavenging from CTM2 to CTM3 also contributes to this by changing the relative distribution of $\mathrm{HNO}_{3}$ throughout the troposphere. In the ssn-simulations, we see a reduction of tropospheric $\mathrm{HNO}_{3}$ by about $28 \%$ in CTM2 and $32 \%$ in CTM3. This agrees well with what we found for $\mathrm{OH}$ and lifetime of $\mathrm{CH}_{4}$. The slightly higher effect on $\mathrm{HNO}_{3}$ in CTM3 is probably due to the less efficient wet scavenging in CTM3 also affecting sea salt and nitrate aerosols, allowing more $\mathrm{HNO}_{3}$ to be bound in nitrate particles. Also important are differences in other loss processes such as photodissociation and the loss to $\mathrm{OH}$.

The higher $\mathrm{HNO}_{3}$ burden in CTM3 is not distributed evenly. In the tropics, below $400 \mathrm{hPa}, \mathrm{HNO}_{3}$ is about $50 \%$ lower in CTM3, while in the extra-tropics CTM3 has up to twice as much $\mathrm{HNO}_{3}$ as in CTM2, consistent with less scavenging. Inclusion of tropospheric aerosols reduces extratropical $\mathrm{HNO}_{3}$ by up to $100 \%$ in both CTM2 and CTM3, slightly more pronounced in CTM3. Because of the less efficient scavenging of sea salt aerosols in $\mathrm{CTM} 3$, more $\mathrm{HNO}_{3}$ is taken up to form nitrate aerosols, explaining this difference.
Above $200 \mathrm{hPa}$, in the stratosphere, CTM3 has about half of the $\mathrm{HNO}_{3}$ in CTM2, except in the upper stratosphere, where CTM3 again has somewhat higher $\mathrm{HNO}_{3}$.

The higher $\mathrm{OH}$ in CTM3 than in CTM2 is partly due to less removal of $\mathrm{H}_{2} \mathrm{O}_{2}$; the CTM3 burden of $\mathrm{H}_{2} \mathrm{O}_{2}$ is $\sim 12 \%$ higher than for CTM2. Spatially, this difference comes from a decrease of $\sim 20 \%$ in the tropical troposphere, but an increase of up to $400 \%$ in the upper troposphere due to lack of scavenging by ice. The more active photochemistry in fastJX may dissociate more $\mathrm{HNO}_{3}$ to $\mathrm{NO}_{\mathrm{x}}$, which again contributes to increasing $\mathrm{OH}$ and thereby to $\mathrm{HNO}_{3}$ loss, but as already mentioned, it has not been possible to separate the effects of differences in scavenging and photochemistry.

\subsection{Transport sensitivity studies}

In order to document the differences in transport schemes between CTM2 and CTM3, we have carried out several 14month sensitivity studies, listed in Table 2 . Here we summarize the findings of shortening the operator-split time step and of using the more accurate polar cap transport in C3_pole.

When halving the CTM 3 operator-split time step to $30 \mathrm{~min}$ (C3_1/2), the computing time is increased by almost $100 \%$ because all processes are done twice. In general there are small differences between $\mathrm{C} 3$ and C3_1/2, except that the SH polar vortex edge seems to be better resolved in C3_1/2, with a sharper gradient across the vortex edge. Total $\mathrm{O}_{3}$ hole column values at the polar side of the $\mathrm{SH}$ vortex edge are reduced by up to $20 \%$, while on the mid-latitude side the column values are increased by up to $5 \%$. These relatively large changes are only found across the sharp gradients, corresponding well with what was seen for age of air. A $15 \mathrm{~min}$ operator-split time step, compared to $60 \mathrm{~min}$, increases these numbers to $25 \%$ and $9 \%$, respectively, showing rapid convergence to CTM2, as was shown in Sect. 3.1.2. A similar effect can also be seen in the Northern Hemisphere, however to a smaller extent. The largest differences occur at mid to high latitudes between $300 \mathrm{hPa}$ and $20 \mathrm{hPa}$, in $\mathrm{O}_{3}$ hole conditions with strong asymmetric vorticies. Here, as we have discussed, the jets may overshoot. When halving the operator-split time step, the maximum increase outside the vortex and the maximum decrease inside the vortex are of the same order: In SH, this maximum change from $\mathrm{C} 3$ to C3_ $1 / 2$ is $\sim 25 \%$, enhanced further by $10-15 \%$ for C3_1/4. In $\mathrm{NH}$ these numbers are smaller $(<1 / 2)$.

A halving of only the horizontal transport time step has also been tested, and found to produce somewhat sharper vortex gradients, although not to the same extent as for C3_1/2. This indicates that vertical transport is important for a better resolved vortex edge.

Using the more accurate polar transport (C3_pole) increases the computing time by about $50 \%$. Hence, not all model time steps require shorter transport time steps than for C3. The changes from $\mathrm{C} 3$ are small, and generally confined to the polar cap. However, the shorter transport time steps 
produce a somewhat sharper gradient across the vortex edge than for C3. C3_pole may impose a shorter global transport time step, but keeps the operator-split time step unchanged. Thus, transport will essentially be similar to C3_1/2 when the transport time step is reduced, but still carried out for $60 \mathrm{~min}$ before chemistry is calculated. However, if the global transport time step does not need to change, it may be that the internal transport step (1-D pipe flow) requires a shorter time step, but this will not produce large differences between $\mathrm{C} 3$ and C3_pole. Again, this was also seen for the age of air studies.

Studies involving stratospheric polar cap transport in T42 horizontal resolution $\left(\sim 2.8^{\circ}\right)$, e.g., Arctic and Antarctic $\mathrm{O}_{3}$ loss studies, will clearly benefit from using the $\mathrm{C} 3$ _pole version combined with a shorter operator-split time step (e.g., C3_1/2), depending on the required accuracy at the vortex. When reduced accuracy at the vortex gradients is acceptable, e.g., when computational costs would otherwise prevent a calculation, the standard setup (C3) should be used. However, at higher horizontal resolutions, e. g. T159, the need of C3_pole may be reduced because $\mathrm{C} 3$ will have better effective polar resolution $\left(\sim 2.2^{\circ}\right)$ and accuracy than $\mathrm{C} 3$ _pole at T42.

\subsection{Computational efficiency}

Part of the motivation for updating the Oslo CTM2 was to make the transport faster, allowing long or complex chemistry simulations. To determine how much faster the Oslo CTM3 is than CTM2, and how well they scale to the number of CPUs used, we have carried out tests for the T42L60 dataset used. Both models are run for one month (January 2005), a month which was found to represent model transport times well, on an Intel Xeon with 32 X7560 $2.27 \mathrm{GHz}$ CPUs.

While the CTM2 transport is parallelized over number of tracers, CTM3 is parallelized over pre-defined horizontal blocks, except for the horizontal transport which is parallelized over model vertical layers. This allows the CTM3 to be run in parallel even for one tracer, and because most processes can be treated in horizontal blocks, matching the number of blocks to a multiple of the number of CPUs allows for a more efficient parallel code. This is an important improvement, making the CTM3 more flexible for using a higher number of CPUs.

Full chemistry simulations with CTM2 and CTM3 (C3) were timed for T42L60 resolution, and CTM3 was found to be about $40 \%$ faster than CTM2. Pure transport tests reveal closer to $50 \%$ improvement, indicating that processes related to chemistry and diagnostics, which are now more realistic, take more time in Oslo CTM3 than in CTM2. The main contributors to this are the stratospheric microphysics, which is treated with a time step of $15 \mathrm{~min}$ instead of one hour in CTM2, but to some extent also the fast-JX cloud overlap treatment, as described in Sect. 2.4.
Both models scale rather well with number of CPUs; a doubling of CPUs generally makes the runs $\sim 40 \%$ faster. However, the gain is reduced dramatically for the CTM2 full chemistry run when shifting from 16 to 32 CPUs due to the number of transported tracers badly matching the numbers of CPUs. CTM3 shows only a slightly lower improvement from 16 to 32 CPUs than from 8 to 16 CPUs. Increasing the number of CPUs also makes the fractional time spent on nonparallelized processes larger, which could also explain some of the inefficiency of increasing CPU numbers.

Pure transport simulations are also carried out in a higher horizontal resolution, namely T159L60 $\left(1.125^{\circ} \times 1.125^{\circ} \mathrm{de}-\right.$ grees), showing a larger reduction $(\sim 60 \%)$ in computing time from CTM2 to CTM3 than at T42L60 resolution. Hence, high resolution simulations have become more feasible with the Oslo CTM3.

\section{Discussion and conclusions}

We have presented the chemical transport model Oslo CTM3 and documented the changes from the earlier version Oslo CTM2. The Oslo CTM3 provides a large improvement of the Oslo CTM2, due to updated and more physically based parameterizations, cleaner code, and increased computational efficiency due to the new structure. The latter makes the Oslo CTM3 better suited for parallelization and up to $40 \%$ faster, enabling much higher spatial resolution or multi-year ensemble/sensitivity simulations. CTM3 also has improved the representation of sub-grid processes such as convection, scavenging, and fractional cloud cover. Thorough evaluation of the Oslo CTM3 against the Oslo CTM2 and against measurements shows that the new version is as good as, if not better than, the old model.

Oslo CTM3 allows for stable, large time steps for advection, and this is essential in enabling more complex (e.g., fully coupled stratosphere-troposphere, gas-aerosol) CTM simulations. Nevertheless, the larger time steps result in larger errors, particularly near the jets where a curving flow may partly overshoot (Prather et al., 2008). When necessary, these errors can be reduced by using a shorter operator-split time step (or advection time step) in the Oslo CTM3.

Stratospheric age of air compare well between CTM2 and CTM3. The oldest age of air in CTM3 is about $5.8 \mathrm{yr}$, slightly lower than in CTM2 (5.9 yr). The spatial distributions are similar in CTM2 and CTM3, except close to the Southern Hemisphere polar vortex edge. We have shown that reducing the transport time step causes CTM3 to converge to CTM2 results at equivalent time steps.

In general, Oslo CTM3 represents the stratosphere better than CTM2 due to the update to fast-JX. Total $\mathrm{O}_{3}$ columns and burdens compare well with measurements and other model studies. In the troposphere there are some model differences due to differences in photochemical reaction rates and also due to different schemes for wet scavenging by rain. 
The CTM3 wet scavenging scheme is more physically based than the old version, although it removes $20-50 \%$ less of soluble species from the troposphere. CTM3 separates largescale scavenging by ice and rain, but the only species subject to ice scavenging is $\mathrm{HNO}_{3}$. Because CTM2 assumes all precipitation to be rain, it generally scavenges more than CTM3 does. As a consequence, with only the tropospheric and stratospheric chemistry schemes included, $\mathrm{NO}_{\mathrm{x}}$ is somewhat increased and $\mathrm{OH}$ is slightly high, giving a corresponding shorter $\mathrm{CH}_{4}$ lifetime with respect to $\mathrm{OH}$ ( $8 \mathrm{yr}$ ). Including sulfur chemistry and nitrate aerosols increases the $\mathrm{CH}_{4}$ lifetime by $\sim 12 \%$ to $8.9 \mathrm{yr}$. We find that increasing anthropogenic CO emissions in the RETRO dataset by $20 \%$ cannot reduce $\mathrm{OH}$ in CTM3 by more than $\sim 1 \%$, and does not affect the $\mathrm{CH}_{4}$-lifetime much. With the improvement to fastJX and the new scavenging in CTM3, it may be that CTM2 has a longer $\mathrm{CH}_{4}$-lifetime for the wrong reasons, e.g., by distributing lightning NOx incorrectly.

The new stratosphere to troposphere flux calculation through the $120 \mathrm{ppb} \mathrm{O}_{3}$ surface yields a somewhat low value of $\sim 300 \mathrm{Tg}\left(\mathrm{O}_{3}\right) \mathrm{yr}^{-1}$ for the year 2005 . Halving the transport time step reduces the STE slightly. Using an older cycle of ECMWF meteorological data yields a higher flux more consistent with the semi-empirical STE fluxes of Murphy and Fahey (1994) and Olsen et al. (2001). This, and the model underestimate of $\mathrm{N}_{2} \mathrm{O}$ compared with satellite observations, indicate that the ECMWF IFS cycle 36r1 has a degraded performance in the stratosphere with a too slow Brewer-Dobson circulation, especially for tropical upwelling. It has not been possible to test the newer cycle 38 . We have also shown that turning off PSC heterogeneous chemistry increases the calculated STE, partly due to changing of the $120 \mathrm{ppb}$ surface. A new surface for calculating STE has been introduced, namely the tropopause defined by the e90-tracer (Prather et al., 2011), which produces STE close to the STE using the $120 \mathrm{ppb} \mathrm{O}_{3}$ isopleth.

Two polar cap transport treatments are available, and when studying polar cap transport care should be taken to use the most accurate method. Reducing the transport time step results in sharper polar vortex edges, and should be considered when studying processes close to or inside polar vortices.

It should be mentioned that the Oslo CTM3 also can be run without stratospheric chemistry, following a similar approach as in Skeie et al. (2011), using a model climatology for stratospheric $\mathrm{O}_{3}$ and $\mathrm{NO}_{\mathrm{x}}$ from a simulation with tropospheric and stratospheric chemistry. This would make the simulations faster due to fewer transported species, and may be an option for studies of the lower to middle troposphere, where the importance of the stratosphere is small.

\section{Supplementary material related to this article is available online at: http://www.geosci-model-dev.net/5/ 1441/2012/gmd-5-1441-2012-supplement.pdf.}

Acknowledgements. Thanks to the MLS team at the Jet Propulsion Laboratory, NASA, for providing satellite data, and also TOMS and OMI for providing $\mathrm{O}_{3}$ columns.

Thanks to Meteorological Service of Canada, Alfred Wegener Institute - Ny Alesund, UK Meteorological Office, and Royal Meteorological Institute of Belgium for making $\mathrm{O}_{3}$ sonde measurements available through the World Ozone and Ultraviolet Radiation Data Centre (WOUDC). Also thanks to SHADOZ for providing additional sonde measurements.

We thank the CARIBIC team for making their measurements available for model comparisons.

Thanks to Environment Canada (doug.worthy@ec.gc.ca) for providing CO measurements from Alert at the WMO World Data Center for Greenhouse Gases (used in the Supplement).

$\mathrm{CO}$ data measured by the Hohenpeißenberg Meteorological Observatory (stefan.gilge@dwd.de, Deutscher Wetterdienst) were obtained from the WMO World Data Center for Greenhouse Gases in Tokyo (used in the Supplement).

We also thank the European Centre for Medium-Range Weather Forecasts for providing meteorological data.

Thanks to L. T. Murray, GEOS-Chem developer at Harvard School of Engineering and Applied Sciences, for the vertical profile routine for lightning $\mathrm{NO}_{\mathrm{x}}$.

The work of OAS was partly funded by the Norwegian Research Council, project number 171218 (Aerosol/gas-phase chemistry and microphysics in global models) and 208277 (Climate and health impacts of Short Lived Atmospheric Components), and also the EU project REACT4C, grant number ACP8-GA-2009-233772.

Edited by: A. Stenke

\section{References}

Allen, D., Pickering, K., Duncan, B., and Damon, M.: Impact of lightning NO emissions on North American photochemistry as determined using the Global Modeling Initiative (GMI) model, J. Geophys. Res., 107, 4711, doi:10.1029/2010JD014062, 2010.

Allen, D. R., Douglass, A. R., Manney, G. L., Strahan, S. E., Krosschell, J. C., Trueblood, J. V., Nielsen, J. E., Pawson, S., and Zhu, Z.: Modeling the Frozen-In Anticyclone in the 2005 Arctic Summer Stratosphere, Atmos. Chem. Phys., 11, 4557-4576, doi:10.5194/acp-11-4557-2011, 2011.

Andreae, M. O. and Merlet, P.: Emissions of trace gases and aeorosols from biomass burning, Global Biogeochem. Cy., 15, 955-966, doi:10.1029/2000GB001382, 2001.

Atkinson, R., Baulch, D. L., Cox, R. A., Crowley, J. N., Hampson, R. F., Hynes, R. G., Jenkin, M. E., Rossi, M. J., and Troe, J.: Evaluated kinetic and photochemical data for atmospheric chemistry: Volume $\mathrm{I}-$ gas phase reactions of $\mathrm{O}_{\mathrm{x}}, \mathrm{HO}_{\mathrm{x}}, \mathrm{NO}_{\mathrm{x}}$ and $\mathrm{SO}_{\mathrm{x}}$ species, Atmos. Chem. Phys., 4, 1461-1738, doi:10.5194/acp-41461-2004, 2004.

Balis, D., Isaksen, I. S. A., Zerefos, C., Zyrichidou, I., Eleftheratos, K., Tourpali, K., Bojkov, R., Rognerud, B., Stordal, F., Søvde, O. A., and Orsolini, Y.: Observed and modelled record ozone decline over the Arctic during winter/spring 2011, Geophys. Res. Lett., 38, L23801, doi:10.1029/2011GL049259, 2011. 
Barret, B., Williams, J. E., Bouarar, I., Yang, X., Josse, B., Law, K., Pham, M., Le Flochmoën, E., Liousse, C., Peuch, V. H., Carver, G. D., Pyle, J. A., Sauvage, B., van Velthoven, P., Schlager, H., Mari, C., and Cammas, J.-P.: Impact of West African Monsoon convective transport and lightning NOx production upon the upper tropospheric composition: a multi-model study, Atmos. Chem. Phys., 10, 5719-5738, doi:10.5194/acp-105719-2010, 2010.

Berglen, T. F., Berntsen, T. K., Isaksen, I. S. A., and Sundet, J. K.: A global model of the coupled sulfur/oxidant chemistry in the troposphere: the sulfur cycle, J. Geophys. Res., 109, D19310, doi:10.1029/2003JD003948, 2004.

Berntsen, T. and Isaksen, I. S. A.: A global 3-D chemical transport model for the troposphere, 1, Model description and CO and Ozone results, J. Geophys. Res., 102, 21239-21280, doi:10.1029/97JD01140, 1997.

Berntsen, T. K. and Isaksen, I. S. A.: Effects of lightning and convection on changes in upper tropospheric ozone due to $\mathrm{NO}_{\mathrm{x}}$ emissions from aircraft, Tellus $\mathrm{B}, 51,766-788$, doi:10.1034/j.1600-0889.1999.t01-3-00003.x, 1999.

Bian, H., Prather, M. J., and Takemura, T.: Tropospheric aerosol impacts on trace gas budgets through photolysis, J. Geophys. Res., 108, 4242, doi:10.1029/2002JD002743, 2003.

Bian, H. S. and Prather, M. J.: Fast-J2: accurate simulation of stratospheric photolysis in global chemical models, J. Atmos. Chem., 41, 281-296, doi:10.1023/A:1014980619462, 2002.

Brenninkmeijer, C. A. M., Crutzen, P., Boumard, F., Dauer, T., Dix, B., Ebinghaus, R., Filippi, D., Fischer, H., Franke, H., Frieß, U., Heintzenberg, J., Helleis, F., Hermann, M., Kock, H. H., Koeppel, C., Lelieveld, J., Leuenberger, M., Martinsson, B. G., Miemczyk, S., Moret, H. P., Nguyen, H. N., Nyfeler, P., Oram, D., O’Sullivan, D., Penkett, S., Platt, U., Pupek, M., Ramonet, M., Randa, B., Reichelt, M., Rhee, T. S., Rohwer, J., Rosenfeld, K., Scharffe, D., Schlager, H., Schumann, U., Slemr, F., Sprung, D., Stock, P., Thaler, R., Valentino, F., van Velthoven, P., Waibel, A., Wandel, A., Waschitschek, K., Wiedensohler, A., Xueref-Remy, I., Zahn, A., Zech, U., and Ziereis, H.: Civil Aircraft for the regular investigation of the atmosphere based on an instrumented container: The new CARIBIC system, Atmos. Chem. Phys., doi:10.5194/acp-74953-2007, 2007.

Christian, H. J., Blakeslee, R. J., Boccippio, D. J., Boeck, W. L., Buechler, D. E., Driscoll, K. T., Goodman, S. J., Hall, J. M., Koshak, W. J., Mach, D. A., and Stewart, M. F.: Global frequency and distribution of lightning as observed by the Optical Transient Dector, J. Geophys. Res., 108, 4005, doi:10.1029/2002JD002347, 2003.

Christian, H. J., Blakeslee, R. J., Goodman, S. J., Mach, D. A., Stewart, M. F., Buechler, D. E., Koshak, W. J., Hall, J. M., Boeck, W. L., Driscoll, K. T., and Bocippio, D. J.: The lightning imaging sensor, in: Proceedings of the 11th International Conference on Atmospheric Electricity, Guntersville, Alabama, 746-749, 1999b.

Dalsøren, S. B., Endresen, Ø., Isaksen, I. S. A., Gravir, G., and Sørgård, E.: Environmental impacts of the expected increase in sea transportation, with a particular focus on oil and gas scenarios for Norway and Northwest Russia, J. Geophys. Res., 112, D02310, doi:10.1029/2005JD006927, 2007.
Dalsøren, S. B., Eide, M. S., Myhre, G., Endresen, Ø., Isaksen, I. S. A., and Fuglestvedt, J. S.: Impacts of the large increase in international ship traffic 2000-2007 on tropospheric ozone and methane, Environ. Sci. Technol., 44, 2482-2489, doi:10.1021/es902628e, 2010.

Dentener, F. and Crutzen, P.: Reaction of NO on Tropospheric Aerosols: Impact on the Global Distributions of NO, O, and OH, J. Geophys. Res., 98, 7149-7163, doi:10.1029/92JD02979, 1993.

Ebinghaus, R., Slemr, F., Brenninkmeijer, C. A. M., van Velthoven, P., Zahn, A., Hermann, M., O’Sullivan, D. A., and Oram, D. E.: Emissions of gaseous mercury from biomass burning in South America in 2005 observed during CARIBIC flights, Geophys. Res. Lett., 34, L08813, doi:10.1029/2006GL028866, 2007.

Froidevaux, L., Jiang, Y. B., Lambert, A., Livesey, N. J., Read, W. G., Waters, J. W., Browell, E. V., Hair, J. W., Avery, M. A., McGee, T. J., Twigg, L. W., Sumnicht, G. K., Jucks, K. W., Margitan, J. J., Sen, B., Stachnik, R. A., Toon, G. C., Bernath, P. F., Boone, C. D., Walker, K. A., Filipiak, M. J., Harwood, R. S., Fuller, R. A., Manney, G. L., Schwartz, M. J., Daffer, W. H., Drouin, B. J., Cofield, R. E., Cuddy, D. T., Jarnot, R. F., Knosp, B. W., Perun, V. S., Snyder, W. V., Stek, P. C., Thurstans, R. P., and Wagner, P. A.: Validation of aura microwave limb sounder stratospheric ozone measurements, J. Geophys. Res., 113, D15S20, doi:10.1029/2007JD008771, 2008.

Gauss, M.: Impact of aircraft emissions and ozone changes in the 21st century: 3-D model studies, Ph.D. thesis, University of Oslo, Department of Geophysics, Section of Meteorology and Oceanography, PB. 1022 Blindern, 0315 Oslo, Norway, ISSN 1501-7710, No. 304, 2003.

Gauss, M., Isaksen, I. S. A., Wong, S., and Wang, W. C.: Impact of $\mathrm{H}_{2} \mathrm{O}$ emissions from cryoplanes and kerosene aircraft on the atmosphere, J. Geophys. Res., 108, 4304, doi:10.1029/2002JD002623, 2003.

Gauss, M., Isaksen, I. S. A., Lee, D. S., and Søvde, O. A.: Impact of aircraft $\mathrm{NO}_{\mathrm{x}}$ emissions on the atmosphere - tradeoffs to reduce the impact, Atmos. Chem. Phys., 6, 1529-1548, doi:10.5194/acp-6-1529-2006, 2006.

Gettelman, A., Holton, J. R., and Rosenlof, K. H.: Mass fluxes of $\mathrm{O}_{3}, \mathrm{CH}_{4}, \mathrm{~N}_{2} \mathrm{O}$, and $\mathrm{CF}_{2} \mathrm{Cl}_{2}$ in the lower stratosphere calculated from observational data, J. Geophys. Res., 102, 19149-19159, doi:10.1029/97JD01014, 1997.

Granier, C., Lamarque, J. F., Mieville, A., Müller, J. F., Olivier, J., Orlando, J., Peters, J., Petron, G., Tyndall, G., and Wallens, S.: POET, a database of surface emissions of ozone precursors, available on internet at http://www.aero.jussieu.fr/projet/ ACCENT/POET.php last access: January 2005.

Grini, A., Myhre, G., Sundet, J. K., and Isaksen, I. S. A.: Modeling the annual cycle of sea salt in the global 3-D model Oslo CTM-2, J. Climate, 15, 1717-1730, doi:10.1175/15200442(2002)015<1717:MTACOS>2.0.CO;2, 2002.

Grini, A., Myhre, G., Zender, C., and Isaksen, I. S. A.: Model simulation of dust sources and transport in the global atmosphere. Effects of soil erodibility and wind speed variability, J. Geophys. Res., 110, D02205, doi:10.1029/2004JD005037, 2005.

Hall, T. M. and Prather, M. J.: Simulations of the trend and annual cycle in stratospheric $\mathrm{CO}_{2}$, J. Geophys. Res., 98, 10573-10581, 
doi:10.1029/93JD00325, 1993.

Hall, T. M. and Prather, M. J.: Seasonal evolutions of $\mathrm{N}_{2} \mathrm{O}$, $\mathrm{O}_{3}$, and $\mathrm{CO}_{2}$ : Three-dimensional simulations of stratospheric correlations, J. Geophys. Res., 100, 16699-16720, doi:10.1029/94JD03300, 1995.

Hall, T. M., Waugh, D. W., Boering, K. A., and Plumb, R. A.: Evaluation of transport in stratospheric models, J. Geophys. Res., 104, 18815-18839, doi:10.1029/1999JD900226, 1999.

Hesstvedt, E., Hov, Ø., and Isaksen, I. S. A.: Quasi steady-state approximation in air pollution modelling: Comparison of two numerical schemes for oxidant prediction, Int. J. Chem. Kinetics, X, 971-994, doi:10.1002/kin.550100907, 1978.

Hodnebrog, Ø., Berntsen, T. K., Dessens, O., Gauss, M., Grewe, V., Isaksen, I. S. A., Koffi, B., Myhre, G., Olivié, D., Prather, M. J., Pyle, J. A., Stordal, F., Szopa, S., Tang, Q., van Velthoven, P., Williams, J. E., and Ødemark, K.: Future impact of non-land based traffic emissions on atmospheric ozone and $\mathrm{OH}$ - an optimistic scenario and a possible mitigation strategy, Atmos. Chem. Phys., 11, 11293-11317, doi:10.5194/acp-11-11293-2011, 2011.

Holton, J. R., Haynes, P. H., McIntyre, M. E., Douglass, A. R., Rood, R. B., and Pfister, L.: Stratosphere-troposphere exchange, Rev. Geophys., 33, 403-439, doi:10.1029/95RG02097, 1995.

Holtslag, A. A. M., DeBruijn, E. I. F., and Pan, H.-L.: A high resolution air mass transformation model for short-range weather forecasting, Mon. Weather Rev., 118, 1561-1575, doi:10.1175/15200493(1990)118<1561:AHRAMT>2.0.CO;2, 1990.

Hooghiemstra, P. B., Krol, M. C., van Leeuwen, T. T., van der Werf, G. R., Novelli, P. C., Deeter, M. N., Aben, I., and Röckmann, T.: Interannual variability of carbon monoxide emission estimates over South America from 2006 to 2010, J. Geophys. Res., 117, D15308, doi:10.1029/2012JD017758, 2012.

Hoor, P., Borken-Kleefeld, J., Caro, D., Dessens, O., Endresen, O., Gauss, M., Grewe, V., Hauglustaine, D., Isaksen, I. S. A., Jöckel, P., Lelieveld, J., Myhre, G., Meijer, E., Olivie, D., Prather, M., Schnadt Poberaj, C., Shine, K. P., Staehelin, J., Tang, Q., van Aardenne, J., van Velthoven, P., and Sausen, R.: The impact of traffic emissions on atmospheric ozone and $\mathrm{OH}$ : results from QUANTIFY, Atmos. Chem. Phys., 9, 3113-3136, doi:10.5194/acp-9-3113-2009, 2009.

Hoyle, C. R., Marécal, V., Russo, M. R., Allen, G., Arteta, J., Chemel, C., Chipperfield, M. P., D’Amato, F., Dessens, O., Feng, W., Hamilton, J. F., Harris, N. R. P., Hosking, J. S., Lewis, A. C., Morgenstern, O., Peter, T., Pyle, J. A., Reddmann, T., Richards, N. A. D., Telford, P. J., Tian, W., Viciani, S., Volz-Thomas, A., Wild, O., Yang, X., and Zeng, G.: Representation of tropical deep convection in atmospheric models Part 2: Tracer transport, Atmos. Chem. Phys., 11, 8103-8131, doi:10.5194/acp-11-8103-2011, 2011.

Hsu, J. and Prather, M. J.: Stratospheric variability and tropospheric ozone, J. Geophys. Res., 114, D06102, doi:10.1029/2008JD010942, 2009.

Hsu, J., Prather, M. J., and Wild, O.: Diagnosing the stratosphereto-troposphere flux of ozone in a chemistry transport model, J. Geophys. Res., 110, D19305, doi:10.1029/2005JD006045, 2005.

HYMN: Hydrogen, Methane and Nitrous oxide: Trend variability, budgets and interactions with the biosphere, Third annual report, D5.2 Report on the influence of the biosphere on trends and variability in $\mathrm{CH}_{4}, \mathrm{H}_{2}$ and $\mathrm{N}_{2} \mathrm{O}$, EU Sixth fracework programme, Project No. 037048 (GOCE), 2010.
IPCC AR4: Climate Change 2007: The Physical Science Basis. Contribution of Working Group I to the Fourth Assessment Report of the Intergovernmental Panel on Climate Change, Cambridge University Press, Cambridge, UK and New York, NY, USA, 996 pp., 2007.

Isaksen, I. S. A., Zerefos, C., Kourtidis, K., Meleti, C., Dalsøren, S. B., Sundet, J. K., Grini, A., Zanis, P., and Balis, D. Tropospheric ozone changes at unpolluted and semipolluted regions induced by stratospheric ozone changes, J. Geophys. Res., 110, D02302, doi:10.1029/2004JD004618, 2005.

Jackman, C. H., Marsh, D. R., Vitt, F. M., Garcia, R. R., Fleming, E. L., Labow, G. J., Randall, C. E., López-Puertas, M., Funke, B., von Clarmann, T., and Stiller, G. P.: Shortand medium-term atmospheric constituent effects of very large solar proton events, Atmos. Chem. Phys., 8, 765-785, doi:10.5194/acp-8-765-2008, 2008.

Jonson, J. E., Sundet, J. K., and Tarrason, L.: Model calculations of present and future levels of ozone and ozone precursors with a global and a regional model, Atmos. Environ., 35, 525-537, doi:10.1016/S1352-2310(00)00314-9, 2001.

Kärcher, B. and Voigt, C.: Formation of nitric acid/water ice particles in cirrus clouds, Geophys. Res. Lett., 33, L08806, doi:10.1029/2006GL025927, 2006.

Kopacz, M., Jacob, D. J., Fisher, J. A., Logan, J. A., Zhang, L., Megretskaia, I. A., Yantosca, R. M., Singh, K., Henze, D. K., Burrows, J. P., Buchwitz, M., Khlystova, I., McMillan, W. W., Gille, J. C., Edwards, D. P., Eldering, A., Thouret, V., and Nedelec, P.: Global estimates of CO sources with high resolution by adjoint inversion of multiple satellite datasets (MOPITT, AIRS, SCIAMACHY, TES), Atmos. Chem. Phys., 10, 855-876, doi:10.5194/acp-10-855-2010, 2010.

Kraabøl, A. G., Berntsen, T. K., Sundet, J. K., and Stordal, F.: Impacts of $\mathrm{NOx}$ emissions from subsonic aircraft in a global three-dimensional chemistry transport model including plume processes, J. Geophys. Res., 107, 4655, doi:10.1029/2001JD001019, 2002.

Labrador, L. J., von Kuhlmann, R., and Lawrence, M. G.: The effects of lightning-produced NOx and its vertical distribution on atmospheric chemistry: sensitivity simulations with MATCHMPIC, Atmos. Chem. Phys., 5, 1815-1834, doi:10.5194/acp-51815-2005, 2005.

Lamarque, J.-F., Bond, T. C., Eyring, V., Granier, C., Heil, A., Klimont, Z., Lee, D., Liousse, C., Mieville, A., Owen, B., Schultz, M. G., Shindell, D., Smith, S. J., Stehfest, E., Van Aardenne, J., Cooper, O. R., Kainuma, M., Mahowald, N., McConnell, J. R., Naik, V., Riahi, K., and van Vuuren, D. P.: Historical (1850-2000) gridded anthropogenic and biomass burning emissions of reactive gases and aerosols: methodology and application, Atmos. Chem. Phys., 10, 7017-7039, doi:10.5194/acp10-7017-2010, 2010.

Lambert, A., Read, W. G., Livesey, N. J., Santee, M. L., Manney, G. L., Froidevaux, L., Wu, D. L., Schwartz, M. J., Pumphrey, H. C., Jimenez, C., Nedoluha, G. E., Cofield, R. E., Cuddy, D. T., Daffer, W. H., Drouin, B. J., Fuller, R. A., Jarnot, R. F., Knosp, B. W., Pickett, H. M., Perun, V. S., Snyder, W. V., Stek, P. C., Thurstans, R. P., Wagner, P. A., Waters, J. W., Jucks, K. W., Toon, G. C., Stachnik, R. A., Bernath, P. F., Boone, C. D., Walker, K. A., Urban, J., Murtagh, D., Elkins, J., and Atlas, E.: Validation of the Aura 
Microwave Limb Sounder stratospheric water vapor and nitrous oxide measurements, J. Geophys. Res., 112, D24S36, doi:10.1029/2007JD008724, 2007.

Livesey, N. J., Read, W. G., Froidevaux, L., Lambert, A., Manney, G. L., Pumphrey, H. C., Santee, M. L., Schwartz, M. J., Wang, S., Cofield, R. E., Cuddy, D. T., Fuller, R. A., Jarnot, R. F., Jiang, J. H., Knosp, B. W., Stek, P. C., Wagner, P. A., and Wu, D. L.: Earth Observing System (EOS) Aura Microwave Limb Sounder (MLS) Version 3.3 Level 2 data quality and description document, Tech. Rep. JPL D-33509, Jet Propulsion Laboratory, California Institute of Technology, Pasadena, California, 91109-8099, available at: http://mls.jpl.nasa.gov (last access: 18 January 2011), 2011.

Macintyre, H. L. and Evans, M. J.: Sensitivity of a global model to the uptake of N2O5 by tropospheric aerosol, Atmos. Chem. Phys., 10, 7409-7414, doi:10.5194/acp-10-7409-2010, 2010.

Manney, G. L., Santee, M. L., Froidevaux, L., Hoppel, K., Livesey, N. J., and Waters, J. W.: EOS MLS observations of ozone loss in the 2004-2005 Arctic winter, Geophys. Res. Lett., 33, L04802, doi:10.1029/2005GL024494, 2006.

Martin, R. V., Jacob, D. J., Yantosca, R. M., Chin, M., and Ginoux, P. J.: Global and regional decreases in tropospheric oxidants from photochemical effects of aerosols, J. Geophys. Res., 108, 4097, doi:10.1029/2002JD002622, 2003.

McCarty, W., Errico, R. M. and Gelaro, R.: Cloud Coverage in the Joint OSSE Nature Run, Mon Weather Rev, 140, 1863-1871, doi:10.1175/MWR-D-11-00131.1, 2012.

McLinden, C. A., Olsen, S. C., Hannegan, B. J., Wild, O., Prather, M. J., and Sundet, J.: Stratosphere ozone in 3-D models: a simple chemistry and the cross-tropopause flux, J. Geophys. Res., 105, 14653-14666, doi:10.1029/2000JD900124, 2000.

Monge-Sanz, B. M., Chipperfield, M. P., Dee, D. P., Simmons, A. J., and Uppala, S. M.: Improvements in the stratospheric transport achieved by a chemistry transport model with ECMWF (re)analyses: identifying effects and remaining challenges, Q. J. Roy. Meteorol. Soc., 138, Early View, doi:10.1002/qj.1996, 2012.

Montzka, S. A., Krol, M., Dlugokencky, E., Hall, B., Jockel, P., and Lelieveld, J.: Small Interannual Variability of Global Atmospheric Hydroxyl, Science, 331, 67-69, doi:10.1126/science.1197640, 2011.

Murphy, D. M. and Fahey, D. W.: An estimate of the flux of stratospheric reactive nitrogen and ozone into the troposphere, J. Geophys. Res., 99, 5325-5332, doi:10.1029/93JD03558, 1994.

Murray, L. T., Jacob, D. J., Logan, J. A., Hudman, R. C. and Koshak, W. J.: Optimized regional and interannual variability of lightning in a global chemical transport model constrained by LIS/OTD satellite data, J. Geophys. Res., 117, D20307, doi:10.1029/2012JD017934, 2012.

Myhre, G., Grini, A., and Metzger, S.: Modelling of nitrate and ammonium-containing aerosols in presence of sea salt, Atmos. Chem. Phys., 6, 4809-4821, doi:10.5194/acp-6-4809-2006, 2006.

Myhre, G., Shine, K., Rädel, G., Gauss, M., Isaksen, I., Tang, Q., Prather, M., Williams, J., van Velthoven, P., Dessens, O., Koffi, B., Szopa, S., Hoor, P., Grewe, V., Borken-Kleefeld, J., Berntsen, T., and Fuglestvedt, J.: Radiative forcing due to changes in ozone and methane caused by the transport sector, Atmos. Environ., 45, 387-394, doi:10.1016/j.atmosenv.2010.10.001, 2011.

Neu, J. L. and Prather, M. J.: Toward a more physical representation of precipitation scavenging in global chemistry models: cloud overlap and ice physics and their impact on tropospheric ozone, Atmos. Chem. Phys., 12, 3289-3310, doi:10.5194/acp-12-32892012, 2012.

Neu, J. L., Prather, M. J., and Penner, J. E.: Global atmospheric chemistry: integrating over fractional cloud cover, J. Geophys. Res., 112, D11306, doi:10.1029/2006JD008007, 2007.

Olivier, J.,Peters, J., Granier, C., Petron, G., Müller, J. F., and Wallens, S: Present and future emissions of atmospheric compounds, POET report \#2, EU report EV K2-1999-00011, 2003.

Olsen, S. C., McLinden, C. A., and Prather, M. J.: Stratospheric $\mathrm{N}_{2} \mathrm{O}-\mathrm{NO}_{\mathrm{y}}$ system: testing uncertainties in a threedimensional framework, J. Geophys. Res., 106, 28771-28784, doi:10.1029/2001JD000559, 2001.

Ott, L. E., Pickering, K. E., Stenchikov, G. L., Allen, D. J., DeCaria, A. J., Ridley, B., Lin, R.-F., Lang, S., and Tao, W.K.: Production of lightning $\mathrm{NO}_{\mathrm{x}}$ and its vertical distribution calculated from three-dimensional cloud-scale chemical transport model simulations, J. Geophys. Res., 115, D04301, doi:10.1029/2009JD011880, 2010.

Owen, B., Lee, D. S., and Lim, L.: Flying into the future: aviation emissions scenarios to 2050, Environ. Sci. Technol., 44, 22552260, doi:10.1021/es902530z, 2010.

Petry, H., Hendricks, J., Möllhoff, M., Lippert, E., Meier, A., Ebel, A., and Sausen, S.: Chemical conversion of subsonic aircraft emissions in the dispersing plume: Calculation of effective emission indices, J. Geophys. Res., 103, 5759-5772, doi:10.1029/97JD03749, 1998.

Pickering, K. E., Wang, Y. S., Tao, W. K., Price, C., and Muller, J. F.: Vertical distributions of lightning $\mathrm{NO}_{\mathrm{x}}$ for use in regional and global chemical transport models, J. Geophys. Res., 103, 31203 31216, doi:10.1029/98JD02651, 1998.

Pison, I., Bousquet, P., Chevallier, F., Szopa, S., and Hauglustaine, D.: Multi-species inversion of $\mathrm{CH}_{4}, \mathrm{CO}$ and $\mathrm{H}_{2}$ emissions from surface measurements, Atmos. Chem. Phys., 9, 5281-5297, doi:10.5194/acp-9-5281-2009, 2009.

Photocomp2008: Chapter 6 - Stratospheric Chemistry in SPARC Report No 5 (2010) in: Chemistry-Climate Model Validation, edited by: Erying, V., Shepherd ,T., and Waugh, D., World Climate Research Programme Report No. 30, World Meteorological Organization TD No. 40, Geneva, http://www.sparc-climate.org/ publications/sparc-reports/sparc-report-no5/, 2010.

Prather, M., McElroy, M., Wofsy, S., Russell, G., and Rind, D.: Chemistry of the global troposphere: fluorocarbons as tracers of air motion, J. Geophys. Res., 92, 6579-6613, doi:10.1029/JD092iD06p06579, 1987.

Prather, M. J.: Fast-JX version 6.5, available at: http://www.ess.uci. edu/ $\sim$ prather/fastJX.html (last access: 1 September 2009), 2009.

Prather, M. J.: Numerical advection by conservation of second-order moments, J. Geophys. Res., 91, 6671-6681, doi:10.1029/JD091iD06p06671, 1986.

Prather, M. J., Zhu, X., Strahan, S. E., Steenrod, S. D., and Rodriguez, J. M.: Quantifying errors in trace species transport modeling, P. Natl. Acad. Sci. USA, 105, 19617-19621, doi:10.1073/pnas.0806541106, 2008.

Prather, M. J., Zhu, X., Tang, Q., Hsu, J., and Neu, J. L.: An atmospheric chemist in search of the tropopause, J. Geophys. Res. 
116, D04304, doi:10.1029/2010JD014939, 2011.

Prather, M. J., Holmes, C. D., and Hsu, J.: Reactive greenhouse gas scenarios: systematic exploration of uncertainties and the role of atmospheric chemistry, Geophys. Res. Lett., 39, L09803, doi:10.1029/2012GL051440, 2012.

Price, C. and Rind, D.: A simple lightning parameterization for calculating global lightning distributions, J. Geophys. Res., 97, 9919-9933, doi:10.1029/92JD00719, 1992.

Randall, C. E., Harvey, V. L., Singleton, C. S., Bernath, P. F., Boone, C. D., and Kozyra, J. U.: Enhanced $\mathrm{NO}_{\mathrm{x}}$ in 2006 linked to strong upper stratospheric Arctic vortex, Geophys. Res. Lett., 33, L18811, doi:10.1029/2006GL027160, 2006.

Randall, C. E., Harvey, V. L., Siskind, D., France, J., Bernath, P., Boone, C. D., and Walker, K.: $\mathrm{NO}_{\mathrm{x}}$ descent in the Arctic middle atmosphere in early 2009, Geophys. Res. Lett., 36, L18811, doi:10.1029/2009GL039706, 2009.

RETRO emissions: REanalysis of the TROpospheric chemical compopsition over the past $40 \mathrm{yr}$, available at: http://retro.enes.org/ (last access: 11 June 2007), 2006.

Sander, S. P., Finlayson-Pitts, B. J., Friedl, R. R., Golden, D. M., Huie, R. E., Keller-Rudek, H., Kolb, C. E., Kurylo, M. J., Molina, M. J., Moortgat, G. K., Orkin, V. L., Ravishankara, A. R., and Wine, P. H.: Chemical Kinetics and Photochemical Data for Use in Atmospheric Studies, Evaluation No. 15, Tech. Rep. 06-2, Jet Propulsion Laboratory, Pasadena, California Institute of Technology, available at: http://jpldataeval.jpl. nasa.gov/ (last access: 6 September 2006), 2006.

Sander, S. P., Abbatt, J., Barker, J. R., Burkholder, J. B., Friedl, R. R., Golden, D. M., Huie, R. E., Kolb, C. E., Kurylo, M. J., Moortgat, G. K., Orkin, V. L., and Wine, P. H.: Chemical Kinetics and Photochemical Data for Use in Atmospheric Studies, Evaluation No. 17, Tech. Rep. 10-06, Jet Propulsion Laboratory, Pasadena, California Institute of Technology, available at: http://jpldataeval.jpl.nasa.gov/ (last access: 10 June 2011), 2011.

Santee, M. L., Lambert, A., Read, W. G., Livesey, N. J., Cofield, R. E., Cuddy, D. T., Daffer, W. H., Drouin, B. J., Froidevaux, L., Fuller, R. A., Jarnot, R. F., Knosp, B. W., Manney, G. L., Perun, V. S., Snyder, W. V., Stek, P. C., Thurstans, R. P., Wagner, P. A., Waters, J. W., Muscari, G., de Zafra, R. L., Dibb, J. E., Fahey, D. W., Popp, P. J., Marcy, T. P., Jucks, K. W., Toon, G. C., Stachnik, R. A., Bernath, P. F., Boone, C. D., Walker, K. A., Urban, J., and Murtagh, D.: Validation of the Aura Microwave Limb Sounder $\mathrm{HNO}_{3}$ measurements, J. Geophys. Res., 112, D24S40, doi:10.1029/2007JD008721, 2007.

Semane, N., Teitelbaum, H., and Basdevant, C.: A very deep ozone minihole in the Northern Hemisphere stratosphere at mid-latitudes during the winter of 2000, Tellus, 54, 382-389, doi:10.1034/j.1600-0870.2002.01380.x, 2002.

Semeniuk, K., Fomichev, V. I., McConnell, J. C., Fu, C., Melo, S. M. L., and Usoskin, I. G.: Middle atmosphere response to the solar cycle in irradiance and ionizing particle precipitation, Atmos. Chem. Phys., 11, 5045-5077, doi:10.5194/acp-11-50452011, 2011.

Shindell, D. T., Faluvegi, G., Stevenson, D. S., Krol, M. C., Emmons, L. K., Lamarque, J.-F., Pétron, G., Dentener, F. J., Ellingsen, K., Schultz, M. G., Wild, O., Amann, M., Atherton, C. S., Bergmann, D. J., Bey, I., Butler, T., Cofala, J., Collins, W. J., Derwent, R. G., Doherty, R. M., Drevet, J.,
Eskes, H. J., Fiore, A. M., Gauss, M., Hauglustaine, D. A., Horowitz, L. W., Isaksen, I. S. A., Lawrence, M. G., Montanaro, V., Müller, J.-F., Pitari, G., Prather, M. J., Pyle, J. A., Rast, S., Rodriguez, J. M., Sanderson, M. G., Savage, N. H., Strahan, S. E., Sudo, K., Szopa, S., Unger, N., van Noije, T. P. C., and Zeng, G.: Multimodel simulations of carbon monoxide: comparison with observations and projected near-future changes, J. Geophys. Res., 111, D19306, doi:10.1029/2006JD007100, 2006.

Skeie, R. B., Berntsen, T. K., Myhre, G., Tanaka, K., Kvalevåg, M. M., and Hoyle, C. R.: Anthropogenic radiative forcing time series from pre-industrial times until 2010, Atmos. Chem. Phys., 11, 11827-11857, doi:10.5194/acp-1111827-2011, 2011.

Solberg, S., Coddeville, P., De Backer, H., C. Forster, Ø. H., Orsolini, Y., Uhse, K., Isaksen, I. S. A., and Søvde, A.: European surface ozone in the extreme summer 2003, J. Geophys. Res., 113, D07307, doi:10.1029/2007JD009098, 2008.

Søvde, O. A., Gauss, M., Smyshlyaev, S. P., and Isaksen, I. S. A.: Evaluation of the chemical transport model Oslo CTM2 with focus on Arctic winter ozone depletion, J. Geophys. Res., 113, D09304, doi:10.1029/2007jd009240, 2008.

Søvde, O. A., Hoyle, C. R., Myhre, G., and Isaksen, I. S. A.: The $\mathrm{HNO}_{3}$ forming branch of the $\mathrm{HO}_{2}+\mathrm{NO}$ reaction: pre-industrialto-present trends in atmospheric species and radiative forcings, Atmos. Chem. Phys., 11, 8929-8943, doi:10.5194/acp-11-89292011, 2011a.

Søvde, O. A., Orsolini, Y. J., Jackson, D. R., Stordal, F., Isaksen, I. S. A., and Rognerud, B.: Estimation of Arctic $\mathrm{O}_{3}$ loss during winter 2006/2007 using data assimilation and comparison with a chemical transport model, Q. J. Roy. Meteorol. Soc., 137, 118-128, doi:10.1002/qj.740, 2011 b.

Stevenson, D. S., Dentener, F. J., Schultz, M. G., Ellingsen, K., van Noije, T. P. C., Wild, O., Zeng, G., Amann, M., Atherton, C. S., Bell, N., Bergmann, D. J., Bey, I., Butler, T., Cofala, J., Collins, W. J., Derwent, R. G., Doherty, R. M., Drevet, J., Eskes, H. J., Fiore, A. M., Gauss, M., Hauglustaine, D. A., Horowitz, L. W., Isaksen, I. S. A., Krol, M. C., Lamarque, J.F., Lawrence, M. G., Montanaro, V., Muller, J.-F., Pitari, G., Prather, M. J., Pyle, J. A., Rast, S., Rodriguez, J. M., Sanderson, M. G., Savage, N. H., Shindell, D. T., Strahan, S. E., Sudo, K., and Szopa, S.: Multimodel ensemble simulations of present-day and near-future tropospheric ozone, J. Geophys. Res., 111, D08301, doi:10.1029/2005JD006338, 2006.

Stordal, F., Isaksen, I. S. A., and Horntvedt, K.: A diabatic circulation two-dimensional model with photochemistry: Simulations of ozone and long-lived tracers with surface sources, J. Geophys. Res., 90, 5757-5776, doi:10.1029/JD090iD03p05757, 1985.

Sundet, J. K.: Model Studies with a 3-D Global CTM using ECMWF data, Ph.D. thesis, University of Oslo, Department of Geophysics, Section of Meteorology and Oceanography, PB. 1022 Blindern, 0315 Oslo, Norway, 1997.

Tabazadeh, A., Toon, O. B., and Jensen, E. J.: A surface chemistry model for nonreactive trace gas adsorption on ice: Implications for nitric acid scavenging by cirrus, Geophys. Res. Lett., 26, 2211-2214, doi:10.1029/1999GL900501, 1999.

Thompson, A. M., Witte, J., McPeters, R., Oltmans, S., Schmidlin, F., Logan, J., Fujiwara, M., Kirchhoff, V., Posny, F., Coetzee, G., Hoegger, B., Kawakami, S., Ogawa, T., Johnson, B., Vömel, H., and Labow, G.: Southern Hemisphere Additional 
Ozonesondes (SHADOZ) 1998-2000 tropical ozone climatology 1. Comparison with Total Ozone Mapping Spectrometer (TOMS) and ground-based measurements, J. Geophys. Res., 108, 8238, doi:10.1029/2001JD000967, 2003.

Tiedtke, M.: A comprehensive mass flux scheme for cumulus parameterisation on large scale models, Mon. Weather Rev., 117, 1779-1800, doi:10.1175/15200493(1989)117<1779:ACMFSF>2.0.CO;2, 1989.

Tost, H., Joeckel, P. J. and Lelieveld, J.: Lightning and convection parameterisations - uncertainties in global modelling, Atmos. Chem. Phys., 7, 4553-4568, doi:10.5194/acp-7-4553-2007, 2007.

Verronen, P. T., Funke, B., López-Puertas, M., Stiller, G. P., von Clarmann, T., Glatthor, N., Enell, C.-F., Turunen, E., and Tamminen, J.: About the increase of $\mathrm{HNO}_{3}$ in the stratopause region during the Halloween 2003 solar proton event, Geophys. Res. Lett., 35, L20809, doi:10.1029/2008GL035312, 2008.

Verronen, P. T., Santee, M. L., Manney, G. L., Lehmann, R., Salmi, S.-M., and Seppala, A.: Nitric acid enhancements in the mesosphere during the January 2005 and December 2006 solar proton events, J. Geophys. Res., 116, D17301, doi:10.1029/2011JD016075, 2011.
Wesely, M. L.: Parameterization of surface resistances to gaseous dry deposition in regional-scale numerical models, Atmos. Environ., 23, 1293-1304, 1989.

Wild, O., Sundet, J. K., Prather, M. J., Isaksen, I. S. A., Akimoto, H., Browell, E. V., and Oltmans, S. J.: Chemical transport model ozone simulations for spring 2001 over the Western Pacific: comparisons with TRACE-P lidar, ozonesondes, and total ozone mapping spectrometer columns, J. Geophys. Res., 108, 8826, doi:10.1029/2002JD003283, 2003.

Williams, E.: Large-scale charge separation in thunderclouds, J. Geophys. Res., 90, 6013-6025, doi:10.1029/JD090iD04p06013, 1985.

Williamson, D. L., Drake, J. B., Hack, J. J., Jakob, R., and Swarztrauber, P. N.: A standard test set for numerical approximations to the shallow water equations in spherical geometry, J. Comput. Phys., 102, 211-224, doi:10.1016/S0021-9991(05)80016-6, 1992. 